\section{International Scientific Journal Theoretical \& Applied Science}

p-ISSN: 2308-4944 (print) $\quad$ e-ISSN: 2409-0085 (online)

Year: $2016 \quad$ Issue: 4 Volume: 36

Published: $30.04 .2016 \quad \underline{\text { http://T-Science.org }}$

SECTION 23. Agriculture. Agronomy. The technique.
Valery I. Glazko

Russian State Agrarian University - Moscow agricultural Academy (MTAA) named after K.A. Timiryazev; Moscow, Russian Federation Head of the Centre of Nanobiotechnology; Centre of Experimental Embryology and Reproductive Biotechnology (CEERB); Russian Academy of Agricultural Science, Moscow, Russian Federation Leading researcher Doctor of Agricultural Sciences, Professor, Academician of Russian Academy of Science (foreign participator) vigvalery@gmail.com

Vladimir G. Sister Moscow Polytechnic University Head of the Department "Processes and devices of chemical technology" Doctor of Technical Sciences, Professor, Corresponding member of RAS vgs001@mail.ru

\title{
BIOGEOSYSTEM TECHNIQUE AS A METHOD TO ATTENUATE THE CONFLICT BETWEEN BIO-, AGRI- AND TECHNO- SPHERES
}

(problem-analytical review)

\begin{abstract}
The Biosphere degrades under outdated technologies. The Biogeosystem Technique is the technical solutions and technologies to maintain the proper biogeochemical cycles of matter in gaseous, liquid, solid form. Biogeosystem Technique is not a direct counterpart to nature. It opens the opportunity to create the nature-similar biogeosistems with transcendental properties:

- synthesize the soil with highly dispersed illuvial horizon of a high stable within period of 30-40 years productivity by intra-soil milling of layer of $20-50 \mathrm{~cm}$;

- increase the rate of environmentally sound recycling in disperse soil system at the same time of intra-soil milling of 20-50 cm layer;

- reduce consumption of fresh water by intra-soil pulse continually-discrete irrigation in the 10-60 cm layer;

- provide the intra-soil pulse continually-discrete fertigation of 10-60 cm soil layer.

Biogeosystem Technique provides priority conditions of plant's development, including horticulture and forestry, low fresh water consumption for bio-products; environmentally sound recycling of matter in the soil dispersed system, increased biological productivity of the biosphere.

Biogeosystem Technique allows consistently solve production and environmental problems in a single technological cycle, to get food growth, to ensure utilization and expanded reproduction of resources, to perform carbon sequestration from the atmosphere by increasing its plants consumption and extending the biospheric carbon phase, to ensure proactive management feedback in the Earth's climate system by varying biological climate drivers. Biogeosystem Technique provides high production results and reduces costs, ensures stability and quality of the biosphere and climate, promotes the long-term economic benefits.
\end{abstract}

Key words: Biosphere, Biogeosystem Technique, soil, irrigation, recycling, food, expanded reproduction of resources, climate, sustainability, economical benefit.

Language: Russian

Citation: Glazko VI, Sister VG (2016) BIOGEOSYSTEM TECHNIQUE AS A METHOD TO ATTENUATE THE CONFLICT BETWEEN BIO-, AGRI- AND TECHNO- SPHERES. ISJ Theoretical \& Applied Science, 04 (36): 46-68.

Soi: http://s-o-i.org/1.1/TAS-04-36-9 Doi: crossef http://dx.doi.org/10.15863/TAS.2016.04.36.9

УДК 631.1:631.459 (470.61): 633.11:551.588: 631.4:574:55:91:33:62

БИОГЕОСИСТЕМОТЕХНИКА КАК МЕТОД ОСЛАБЛЕНИЯ КОНФЛИКТА МЕЖДУ БИО-, АГРОИ ТЕХНО- СФЕРАМИ

(проблемно-аналитический обзор) 
Аннотация: Современная биосфера деградирует под воздействием устаревших технологий. С иелью преодоления конфликта предложена биогеосистемотехника - алгоритм и технологии управления биогеохимическими ииклами вещчеств биогеосистем в газообразной, жидкой, твердой фазе. Технологии биогеосистемотехники не имеют прямых аналогов в природе. Открыта возможность синтезировать природоподбные биогеосистемы с трансиендентальными свойствами:

- внутрипочвенное фрезерование слоя 20-50 см обеспечивает создание почвы с высокой дисперсностью иллювиального горизонта, которая имеет устойчивое в течение 30-40 лет высокое плодородие;

- экологически безопасный рециклинг вещчества внутри почвы в процессе слое 20 -50 см, обеспечивающий оптимизациию геохимического ичикла вещзества Земли, увеличение емкости, повыщение устойчивости и продуктивности биосферы;

импульсный внутрипочвенный континуально-дискретный полив растений, обеспечивающий сохранение почв и ландшафтов, уменьшение потребления воды для ирригации в 10-30 раз, повышение плодородия;

- импульсная внутрипочвенная континуально-дискретная фертигация, обеспечиваюшая орошение и питание растений, рециклинг минеральных и органических отходов.

Биогеосистемотехника обеспечивает приоритетные условия развития растений, включая многолетние насаждения, уменьшение нормы потребления пресной воды на производство биопродукиии; увеличение производительности экологически безопасного рециклинга вещества в дисперсной системе почвы, увеличение биологической продуктивности биосферы.

Биогеосистемотехника позволяет непротиворечиво решать производственнье и экологические проблемы в едином технологическом изиле, получить прирост продовольствия, обеспечить утилизацию и растиренное воспроизводство ресурсов, выполнить секвестр углерода из атмосферы, усилив его потребление растениями и расширив биосферную фазу углерода, обеспечить упреждающее управление обратной связью в климатической системе Земли путем варьирования биологическими драйверами климата. За счет биогеосистемотехники достигается высокий производственный результат и снижение затрат, обеспечивает устойчивость и качество биосферы, климата и долгосрочная экономическая выгода

Ключевые слова: биосфера, биогеосистемотехника, почва, полив, рециклинг, прирост ресурсов и продовольствия, климат, устойчивость.

\section{ВВЕДЕНИЕ}

В России, как и во всём мире, в XXI веке исчерпаны возможности индустриальной эксплуатации урбо-, техно- и агроэкосистем, имеет место конфликт биосферы и человечества [1, 2, 3]. Это обусловлено пренебрежением к геоэтике и геогигиене [4], применением устаревших имитационных принципов природопользования. В итоге разрушение урбо- и агроэкосистем, вероятность безальтернативного деградационного сценария современной биосферы [5].

В мире есть запрос на новый вектор развития $[6,7]$. Для того чтобы не воспроизводить одни и те же ошибки, в качестве стратегического ориентира предложено разрабатывать природоподобные технологии [8]. С одной стороны, посыл многообещающий, но с другой стороны есть опасность, что его могут растащить на цитаты и выхолостить. Посыл предполагает творческий подход к его пониманию и применению, ведь «природоподобный» не означает простое подобие, копирование, требует значительно более широкого осмысления развития мира, особенно с учетом текущей тупиковой ситуации по всем направлениям.

Предложение о природоподобных технологиях возникло не на пустом месте [9]. В 1992 году принята концепция Sustainable Development [10]. После ее принятия на Западе были продолжены разработки в этом направлении, и в 2002 году появился доклад Национального научного фонда и Министерства торговли США о конвергентных технологиях для повышения возможностей человека за счет проведения научных и прикладных исследований в синергетическом междисциплинарном поле «nanotechnology, biotechnology, information technology and cognitive science (NBIC)» «нанотехнология, биотехнология, информационная технология, когнитология» [11]. Во многом на этой основе затем были выработаны принципы «Green Economy», принятой в 2012 году [12]. Обе концепции не соответствуют возлагавшимся на них надеждам, как и концепция нано-, био-, инфо-, когнитивно-, социальной (НБИКС) науки и технологии, ориентированная на то, чтобы через синергетику и постнеклассику приблизиться к природоподобию [13]. Так что природоподобные технологии - это не только политический посыл России, заявление о намерении возглавить процесс мирового развития в области биологии, биосферологии, своевременная реакция РФ на объективный запрос о принципиально новом опережающем развитии страны и мира, но и большой груз ответственности за выбор верного пути решения проблемы природоподобия.

Развитие мира многогранно, обеспечение устойчивости - сложнейшая проблема [14]. 
Слишком велик соблазн упрощенного подхода к развитию, что ведет к отставанию. Оно заложено в NBIC как продукте, по умолчанию ориентированном на модернизацию устаревшей индустриальной технологической платформы потребления ресурсов, и, следовательно, будет воспроизведено в РФ в заимствованном продукте НБИКС. Волну инновации не следует поджидать [15]. Надо создать её принципиально новый источник. И это качество, скачёк никогда не будет следствием детерминированного сочетания известных компонентов синергетического плавного развития [16].

Идеологию развития РФ и мира нельзя понимать упрощенно как продукт нанотехнологической революции, позволяющей пользоваться теми же “технологическими приемами”, которыми пользуется сама природа, и этим обеспечить возврат человека к восприятию мира как единого целого. Природа и её явления значительно сложнее. Можно искать стабильность в рамках старой индустриальной технологической платформы [17], но в результате в мире будет всё шире распространяться голод [18]. Опасность прямой имитации природы доказала история развития цивилизаций.

Трансцендентальный

подход биогеосистемотехники с позиций учения В.И. Вернадского о биосфере позволяет синтезировать принципиально новый технологический базис ноосферы, непротиворечиво встраиваемый в другие геосферы, получить возможность управлять коэволюцией биосферы, её новым высоким качеством для экологичного наращивания технологической активности, производства дополнительных нормативно чистых ресурсов и товаров, расширения ареала высокого качества жизни. В свете развития природоподобных технологий важно обратить внимание политического дискурса на возможности биогеосистемотехники $[19,20]$.

Земля сейчас по большей части - всё разрастающаяся пустыня [21]. Слабые, но расточительные в отношении ресурсов природы и энергии, возможности современных агротехнологий, ирригации, охраны экосферы, тем не менее, не позволяют игнорировать биосферу, замыкаться в биотехнологии, нанотехнологии.

Современная цивилизация неумелым природопользованием отторгает земли у биосферы, теряет пресную воду, деградирует и захламляет почву. Количество отходов, отправляемых на рециклинг, растёт значительно медленнее их продуцирования, в результате рост опустынивания, истощения ресурсов и социального напряжения.

Для непротиворечивого встраивания технологии в биосферу предложена биогеосистемотехника, разработаны не имеющие аналогов в мире технические решения и технологии:

$\checkmark$ роторная фрезерная механическая обработка внутреннего горизонта почвы (20-50 см) позволяет увеличить её плодородие на 30 $80 \%$ до 40 лет, и повысить рентабельность технологии земледелия в 2-3 раза;

$\checkmark$ рециклинг промышленных, бытовых и отходов пищевых производств внутри дисперсной системы до 500 т/га в процессе фрезерной механической обработки её внутреннего горизонта (20-50 см);

$\checkmark$ внутрипочвенная импульсная континуально-дискретная парадигма ирригации, обеспечивающая экономию поливной воды в 5-20 pa3;

$\checkmark$ утилизация внутри почвы опасных биологических отходов, за счет разрыва трофических цепей распространения инфекций обеспечивающая переработку биологического материала почвенными деструкторами, повышающую плодородие и санитарногигиеническую безопасность почвы;

$\checkmark$ стабилизация

климатических флуктуаций.

\section{УПРАВЛЕНИЕ КОЭВОЛЮЦИЕЙ БИОСФЕРЫ}

Современные агротехнологии, в том числе, в агрономии, ирригации, природопользовании имеют ограниченные возможности синтеза биологической продукции и утилизации отходов почвенными экосистемами. Начиная с неолита потеряно 42\% плодородных земель [22], 60\% ресурсов Земли [23]; до 90-95\% пресной воды используется расточительно [24], загрязняются гео- и экосферы $[25,26]$, дестабилизируется климат [27].

Современные технологии имитируют природные явления обработкой верхнего слоя почвы, внесением вещества на её поверхность либо в пахотный горизонт, сбросом неутилизированного вещества в гидросистемы. В итоге - ускоренная минерализация, загрязнение почвы и эвтрофикация водоёмов. Проблему избытка фосфора в сточных водах можно успешно решить их рециклингом через почву, где они станут источником дополнительной биопродукции.

Примитивная, упрощенная имитация природы несёт опасность. Это современное растениеводство, индуцирующее деградацию земель и почв. Это ирригация, в результате которой (без учёта потребностей растений) до 95\% используемой воды теряется, а почвы и ландшафты деградируют. Это утилизация отходов по принципу, что каждый организм избавляется от отходов жизнедеятельности посредством стабильно функционирующих биогеохимических циклов. Мироздание отвело 
человечеству мизерное количество незаменимого вещества, потому именовать его ресурсами, тем более, отходами - недальновидно. Вещество необходимо использовать так, чтобы в процессе так называемых безотходных технологий имел место длительный, лучше - непрерывный - цикл его экологичного обращения в технологии и природе.

Климат Земли в результате слишком вольного поведения человека в биосфере может оказаться в состоянии избыточной флуктуации. Одна из причин - вытекающая из индустриальной технологической платформы потребления задача секвестра углерода из биосферы. Это ведёт к угасанию биосферы, ослабляет её роль буфера климата [28].

Идеология развития в мире не оперирует биосферными категориями. Со значительным запозданием в РФ рассматривают проблемы развития сельского хозяйства, но не в фокусе биосферы, а только с точки зрения производства продовольствия, рассматривают орошение безотносительно сохранения почвы и воды, решают задачу сокращения прошлого экологического ущерба вместо воспроизводства ресурсов. Состояние окружающей среды, не биосфера! оказывается в фокусе внимания только как досадное обстоятельство, сдерживающее развитие производства и потребления. Выдающееся учение В.И. Вернадского о биосфере [29] вообще полагают религиозным течением в силу отсутствия научных методов его реализации [30]. Очевидна необходимость поиска принципиально новой парадигмы развития РФ, ведь биосфере нет альтернативы [5], её, если она падет жертвой конкурентной борьбы за прибыль, нечем будет заменить.

В экологических программах, водном, сельском и муниципальном хозяйствах, промышленности РФ механически применяют заимствованные зарубежные технические средства и технологии, по сути, устаревшие образцы индустриальной технологической платформы [31-33]. Например, современные устройства для внесения в почву удобрений и навоза фирмы Duport [34] представляют собой фактически катки для уплотнения почвы, а это особенно опасно для почв России, и снабжены они устройствами для внесения вещества, разработанными в СССР более 40 лет назад предназначенными для своего времени [35].

Такое положение дел совершенно не соответствует объявленному в РФ курсу на модернизацию страны и задаче синтеза не имеющих аналогов в мире природоподобных технологий. Продолжение сложившейся практики развития приведет к неблагоприятным политическим, экономическим и общественным последствиям, поскольку, по определению, нельзя в чужом русле идти опережающим темпом. Состояние дел порождает резонный вопрос, а нужны ли такие программы развития [36]? Применение устаревших технологий природопользования антиконституционно, оно опасно для текущей и длительной перспективы обоих атрибутов государственности - земель, которые нечем будет заменить, народа, которому следует обеспечить наилучшие условия жизни, творческого эффективного и безопасного труда.

Игнорируя отечественный интеллектуальный продукт, затем приходится закупать его же с Запада, причем с запозданием, плодя собственную отсталость. При таком подходе на устаревшей индустриальной технологической платформе Sustainable Development, Green Economy, новая индустриализация [37], инновационное развитие РФ останутся только лишь красивыми дорогостоящими неисполнимыми декларациями.

Вместо копирования развития, наблюдения очередных приходящих из-за рубежа технологических укладов и инновационных волн, надо применить квалифицированную интуицию, выбрать институциональные эвристические решения. Они обеспечат новую сущность мультипликативного результата развития не просто в виде синергетической суммы его известных факторов, но позволят получить принципиально новые возможности развития, которых нет в природе. И хотя они не будут копированием природы, но дадут новое качество непротиворечивого взаимодействия с природой, и при этом будут природоподобны. Только так можно получить новый опережающий мировой уровень технологический уклад. Успех будет только в том случае, когда принято дальновидное решение о программной поддержке, развитии стратегически важных трансцендентальных артефактов техники, и базирующейся на их основе трансцендентальной технологии. Лишь затем новую успешную технологию можно выводить в контролируемое состояние бизнеспроектов, тиражируя и эволюционно продолжая достижения научно-технического направления. Это позволит синтезировать в РФ технологическую платформу ноосферы целостную систему реализации природоподобных технологий. Непротиворечивое, экологичное встраивание технологий в биосферу обеспечит предложенное нами научно-техническое направление «биогеосистемотехника».

\section{МЕТОД БИОГЕОСИСТЕМОТЕХНИКИ}

Биогеосистемотехника - это технические решения и технологии инновационного управления биогеохимическим циклом вещества биогеосистем в газообразной, жидкой, твердой 
фазах, не имеющие прямых аналогов в природе. Методы биогеосистемотехники не копируют и не имитируют природу, но обеспечивают создание биогеосистем, обладающих трансцендентальными свойствами.

Биогеосистемотехника по сравнению с естественными условиями и известными стандартными имитационными технологиями позволяет активизировать биосферный процесс в педосфере, уменьшить норму потребления пресной воды на производство биологической продукции, увеличить норму экологически безопасного рециклинга вещества в почвах и продуктивность земель за счет возврата вещества в биосферу через почву, получить трансцендентальный высокий прирост ресурсов и продовольствия. Биогеосистемотехника обеспечивает высокую норму экологичной биологической продукции, что повышает устойчивость биосферы и обеспечивает долгосрочную экономическую выгоду.

Биогеосистемотехника отличается от технологий индустриальной платформы тем, что вместо накопления экологических проблем предлагает упреждающие технические и технологические решения, позволяющие при переходе к ноосфере непротиворечиво решать производственные и экологические проблемы в едином технологическом цикле, с большим производственным результатом и меньшими затратами.

Чем большая часть суши будет вовлечена в активный биосферный процесс с помощью методов биогеосистемотехники, тем выше будет уровень стабильности биосферы. Гидрологические и климатические явления станут более предсказуемыми, интенсифицируется круговорот воды, углерода и других биофильных элементов, снизится сток биофильных элементов в водные системы, возрастёт производство кислорода, биопродукции (продовольствия, сырья), оптимизируются условия для новой индустриализации.

Биогеосистемотехника _ _ это инновационное институциональное научнотехническое производственное направление трансцендентального синтеза новых технологий, обеспечивающих создание новых трансцендентальных высокопродуктивных стабильных биогеосистем ноосферы. Биогеосистемотехника обеспечит краткосрочный и долгосрочный горизонт стратегии развития РФ и мира в целом [38, 39].

\section{РЕЗУЛЬТАТЫ И ОБСУЖДЕНИЕ}

\section{а) УЛУЧШЕНИЕ ПЕДОСФЕРЫ}

Турбация почвосубстрата, в котором развивается жизнь, резко увеличивает его потенциальную продуктивность. Однако теория и практика механической обработки почвы не ориентированы на её эволюцию, следуют только из сложившихся особенностей почвы как продукта генезиса - изначальной геологической структуры, прошедшей стадию интенсивного выветривания как геологического отложения на дневной поверхности и впоследствии биологизированной. Управление свойствами дисперсной почвенной системы направлено по имитационному пути и повторяет рыхлящее воздействие на почву геологического выветривания, корня растения или копыта животного. Это существенно упрощает технические решения механической обработки почвы в интересах агропроизводства. Механическая обработка почвы сводится, по существу, не к диспергированию, а преимущественно к перемещению агрегатов почвы.

В результате седиментации происходит исключение биофилов и органического вещества из биогеохимических циклов. Для сложения почв типичной является структура с преобладанием тупиковых пор, составляющих до 99\% всего объема порового пространств [40, 41]. Строение этого пространства почвы, условия пространственного размещение в нём корневой системы культивируемых растений и геобионтов при оценке качества обработки почвы игнорируется. Оценивают по-старому только количество глыб на поверхности почвы размером больше 50 (в некоторых источниках больше 100) мм [42, 43]. Вопрос о диспергировании почвы при её обработке пассивными рыхлителями в агрономической теории и практике не ставится эти устройства позволяют только отделить друг от друга уже имеющиеся агрегаты и в меньшей степени - создать новые. В результате имеет место кризисный вариант управления педосферой: развитие ризосферы стимулируется только в самом верхнем, обработанном горизонте почвы $[44,45]$. Поскольку корни растений вглубь не идут, наступает стагнация агрокультурной дифференциации почвенного профиля из-за ограниченного проникновения в него воды и корней растений. Почва и почвообразующая порода, залегающие глубже обработанного горизонта, постепенно исключаются из биологических процессов, во всяком случае, их участие ослабевает, органическое вещество глубоких горизонтов почвы переходит в стадию седиментации. Это проявляется при использовании no-till [46].

Имитационный подход к технике и технологии рыхления почв даёт неблагоприятные следствия, поскольку при нынешних технических возможностях воздействие ходовой системы тракторов, орудий и другой сельскохозяйственной техники существенно 
превосходит противодействие природных факторов почвообразования. В результате происходит техногенная деградация педосферы, уплотнение, осолонцевание, слитизация и ускоренная эволюции почв и ландшафтов [47-53].

В стандартной агротехнике наблюдается вертикальная дифференциация горизонтов почвы. Глубже 20-25 см корневая система практически не распространяется. Урожайность сельскохозяйственных культур низкая.

В то же время получены фундаментальные данные, позволяющие утверждать, что направленное изменение эволюции почвы возможно [54]. В результате биологическая продуктивность агроценоза может быть увеличена.

Для предотвращения уплотнения почв применяют впервые разработанное и использованное еще в Российской империи щелевание почв. Затем этот агротехнический прием стал известен на Западе, ему дали свое название «чизелевание», chisel (англ.) - долото, теперь под этим именем щелевание применяется в России и мире. Недостаток щелевания состоит в том, что, кроме рыхления почвы непосредственно в щели, оно приводит также к затиранию и дополнительному уплотнению стенок щели. При этом разрушение блоков почвы незначительное. Поэтому щелевание рекомендуют повторять через 2 года, максимум через 4-5 лет [55].

Стандартным техническим решением является трехъярусная мелиоративная обработка почвы на 40-45 см плугом ПТН-40 [56, 57]. Применение трехъярусного плуга обеспечивало лучшие и более долгосрочные, чем щелевание результаты, но рыхление и перемешивание почвы оказалось недостаточным [58], имело место не соответствующее задачам мелиорации и агротехнологии размещение слоев почвы.

В 60-70-х годах 20 века был разработан принцип мелиорации почв, реализующий управление дисперсной системой почвы посредством роторно-фрезерного рыхления мелиорируемого слоя (20-50 cм).

Рабочая гипотеза:

1. Верхний слой почвы в процессе мелиоративной обработки или остается на месте, или обрабатывается по общепринятой технологии. Это исключает дополнительный эрозионный процесс, который мог бы происходить при роторной обработке верхнего слоя почвы.

2. Внутренний слой почвы 20-50 (возможно, 30-60) см обрабатывается путем роторного фрезерного рыхления этих глубоких слоёв, оказывающих в стандартной агротехнике наиболее неблагоприятное воздействие на развитие взрослых культурных растений. Роторное фрезерное рыхление слоя 20-50 см было выбрано как альтернатива трехъярусной мелиоративной вспашке и щелеванию почвы.

3. Наличие устойчивой структуры почвы, каркасом которой являются извлеченные из глубоких горизонтов минеральное вещества и мощная корневая система, обеспечивают повышенную пористость почвы. При этом предотвращается переувлажнение почвы при атмосферных осадках и энергия воды не расходуется на разрушение почвенной структуры. Энергия растений и почвообрабатывающих устройств также не расходуется на восстановление структуры почвы.

В СССР впервые в мире решена задача синтеза нового качества почвы при её агромелиорации с применением роторного фрезерного рыхления, создана серия технических решений. Результат тесно связан со степенью соответствия технического решения природе почвы и прогнозу последующей эволюции [59].

Устройства, разработанные в Донском сельскохозяйственном институте (ДСХИ) ПМС70, ПМС-10, ПМС-100М, ФС-1,3, как и некоторые другие [60], были выполнены с горизонтальным валом, оборудованном фрезами. Принцип рыхления и перемешивания горизонтов почвы снизу вверх. Первым из серии технических решений был почвенно-мелиоративный роторный фрезерный плуг ПМС-70, оборудованный механическим приводом, рыхлящим ножом, редукторной стойкой, роторно-фрезерным рыхлителем иллювиального и подсолонцового горизонтов почвы, пассивным плужным корпусом для обработки верхнего слоя почвы. После однократной почвенно-мелиоративной внутрипочвенной роторной фрезерной обработки искусственные мелкие агрегаты почвы представляют собою комфортный субстрат для развития корневой системы растений и геобионтов.

Ведомственные испытания серии машин показали перспективность роторной фрезерной обработки почв тяжелого гранулометрического состава с перемешиванием внутренних слоев [58]. На основании разработок, выполненных в ДСХИ и других учреждениях, в конце 70-х годов была запущена в серию мелиоративная машина МСП-2 Целиноградского СКБ ПЭТ [61].

Стационарные производственные эксперименты свидетельствуют, что агромелиорация почв орудиями с роторными фрезерными рабочими органами, расположенными на горизонтальном вале и работающими с полным погружением в обрабатываемый слой 20-45 см, обеспечивает улучшение биологических и технологических параметров, стабильно высокую прибавку урожайности и высокие экономические показатели в течение до 40 лет [62, 63]. Они 
превышают показатели стандартной и типовой мелиоративной агротехники (табл.). Длительность эффекта позволяет вести речь о новом векторе эволюции почвы.

Недостаток рассмотренных устройств для обработки почвы - большое тяговое сопротивление, обусловленное вертикальным редуктором привода фрезерного рыхлителя, выполненного в виде пассивной рыхлящей стойки. Вариант преодоления проблемы высокого тягового сопротивления - фреза с вертикальным валом имеет недостаток уплотнение почвы под фрезой.

Таблица 1

Экономические показатели, 2006 г., озимая пшеница, стационар 1976 г. Колхоз имени XVII Партконференции (ООО Мир), Ремонтное, Ростовская область.

\begin{tabular}{|c|c|c|c|}
\hline Показатель & $\begin{array}{c}\text { Отвальная } \\
\text { обработка } \\
0-22 \text { см } \\
\end{array}$ & $\begin{array}{c}\text { ПТН- } 40, \\
0-45 \mathrm{~cm}\end{array}$ & $\begin{array}{l}\mathrm{\Phi C}-1,3, \\
20-45 \mathrm{~cm}\end{array}$ \\
\hline Урожайность, т/га & 4,14 & 5,12 & 6,58 \\
\hline Прибавка урожайности, т/га & 0 & 0,98 & 2,44 \\
\hline Прибавка урожайности, \% & 0 & 23,7 & 58,9 \\
\hline Цена, руб/т & 4700,00 & 4700,00 & 4700,00 \\
\hline $\begin{array}{c}\text { Приведённые } \\
\text { ценах, руб/га }\end{array}$ & 0 & 9000,00 & 16000,00 \\
\hline Срок действия агромелиорации, лет & 0 & 10 & 30 \\
\hline Приведенные затраты амортизации, руб/га & 0 & 900 & 533,33 \\
\hline Затраты всего, руб/га & 15900,00 & 19750,00 & 19883,33 \\
\hline Рентабельность, \% & 22,4 & 22,9 & 57,1 \\
\hline Себестоимость, руб/т & 3840,58 & 3857,42 & 3021,78 \\
\hline
\end{tabular}

Итак, на основе многолетних исследований предложено новое техническое решение, обеспечившее обработку внутреннего слоя почвы. Сохранено хорошо показавшее себя техническое решение - горизонтальный ротор с фрезами. Предложен принципиально новый принцип привода вала внутрипочвенного фрезерного рыхлителя - роторный кольцевой щелерез-редуктор, исключающий пассивное сопротивление перемещению устройства в почве [64, 65].

Новое исполнение привода обеспечивает повышение надежности устройства [66, 67], прирост удельной производительности (на единицу ширины захвата) в 2 раза по сравнению с прежними разработками. Имеется возможность решить современную проблему strip-till [68] с использованием активных рабочих органов [69].

История и состояние теории и практики мелиоративной обработки почвы показывает актуальность создания в почве новых дисперсных систем как источника питательных веществ, повышающих биопродуктивность почвы и коэффициенты использования минеральных удобрений $\quad$ [70, 71]. Предотвращаются безвозвратные потери органического вещества из педосферы в процессе его природной седиментации в иллювиальном горизонте почвы. Внутрипочвенное роторное фрезерное рыхление позволяет создавать в почве дисперсную систему с заданными структурными свойствами и вещественным составом. Методами биогеосистемотехники обеспечивается новый стабильный вектор техноэволюции почвы. Открывается возможность не только адаптировать технологию к ландшафту, но и оптимизировать, адаптировать ландшафт к задачам интеграции современной природоподобной технологии [72].

$$
\text { б) ВОДНАЯ СТРАТЕГИЯ }
$$

Современную водную стратегию мира отличает двойственность. С одной стороны, пресная вода - глобальный дефицитный природный ресурс. С другой стороны, широко практикуются расточительные технологии использования воды, а гидрологические прогнозы характеризуются повышенной степенью неопределенности [73-75].

Парниковые газы опасны для цивилизации, причём самый опасный из них - водяной пар [27]. Поэтому глобальная водная стратегия должна 
быть ориентирована не только на сбережение воды, но и на сокращение ее избыточного испарения в атмосферу. Ведущим потребителем пресной воды на Земле является ирригация, потребляющая до 95\% общемирового ресурса. При этом $\geq 90 \%$ воды при ирригации используется непроизводительно, во вред геосферам [24]. В то же время, вода является источником жизни на Земле, фактором эволюции почвенного покрова. Поэтому гидрологический режим биосферы оказался привлекательным объектом для копирования природы имитационной парадигмы стандартной ирригации, которая основана на воспроизведении нисходящего (или восходящего) фронтального гравитационного режима промачивания почвы. В результате воспроизводятся отрицательные последствия избыточного длительного переувлажнения почвенного экотопа [76].

Действующая парадигма ирригации может быть охарактеризована как имитационная гравитационная фронтальная континуальноизотропная, еe применение обусловливает долгосрочные отрицательные результаты, приводит к экологическим и гуманитарным катастрофам.

Всё сказанное - следствие системной особенности гидрологического режима биосферы - совмещения фазы подачи воды к почве в виде в той или иной степени сконцентрированного водного потока с фазой его растекания, точнее, диссипации воды внутри почвы. В природе этот процесс идет случайным образом. Потому пространственная картина гидрологического режима в масштабе территории, ландшафта, ареала почвы всегда несет элемент неопределённости. Для природы это - приоритет - драйвер биологического разнообразия за счёт разнообразия гидрологического режима суши. Потому фронтальная непрерывная подача воды в ненарушенную почву, которую с успехом использует Природа для поддержания биологического разнообразия, в принципе не соответствует задаче управляемого режима равномерного распределения воды между элементами дисперсной системы почвы, необходимого для унифицированного питания растений водой и биофильными элементами. Следовательно, артефакты цивилизации, предназначенные для управления потоками воды в почве, не должны имитировать природные процессы.

Отрицательный результат ирригации в исторической ретроспекции обусловлен тем, что в рамках её действующей парадигмы непреодолимы: а) нарушение гидрологического и гидрогеологического режимов ландшафта, б) избыточное выщелачивание питательных веществ из почвы, в) ирригационное переувлажнение и засоление почвы, г) гравитационно-гидродинамическая флотация твердой фазы почвы, д) гравитационное водное переуплотнение, е) прирост геохимического охвата ландшафта и другие негативные явления. Результаты применения имитации увлажнения почв в целях повышения их продуктивности путем ирригации в настоящее время абсолютно неприемлемы. Расходование пресной воды при ирригации расточительное - в 5-15 раз больше эмпирически назначенной ирригаторами потребности растений в воде [77, 78].

Расход воды на ирригацию составляет от 5 $360 \mathrm{~m}^{3} /$ га в год в рациональном Израиле, в США - до 19 000, в Индии -10 000, Египте - 17750 , Китае - от 13100 и до 25 300-42 400 м³/га в год, причем без учета культуры риса [24].

Сама расчетная эмпирическая потребность растений в воде завышена. Хлопчатник, который является ксерофитным растением (!), повсеместно поливают избыточно, и это одна из причин исчезновения Аральского моря и угрозы Амударье. Аналогичная ситуация в бассейнах Колорадо, Сакраменто. Сток Рио-Гранде забирают США, причем в ущерб и самим себе, и Мексике. Появление болот в результате орошение на месте пустынь - это не частный случай, а универсальное следствие дефекта современной парадигмы ирригации.

Проблема избыточного полива при ирригации - давний предмет общественного и научного обсуждения. В целях экономии воды пытаются снижать поливные нормы, возвращать использованную воду в ирригационный цикл, применять гидроциклическую ирригацию, однако подход совершенно неприемлем - он не решает проблему фронтального гравитационного избыточного увлажнения почвы, преференсных потоков воды [79]. Частичная модернизация в рамках устаревшей парадигмы путем переработки нормативов мелиорации, предпринятая недавно РАСХН, неработоспособна [80]. Есть удручающий своей безысходностью вариант - вместо ирригации разводить саксаул [81].

Констатируем, что проблема управления гидрологическим режимом педосферы для обеспечения нового вектора эволюции орошаемых почв как основная составляющая парадигмы ирригации и водной стратегии мира до настоящего времени не решена [82-85]. Её суть - обеспечить растение минимальным дополнительным количеством воды и получить максимальный уровень биопродукции (общей и товарной). При этом почва будет сохранена и улучшена, вода будет возвращена в атмосферу только путем транспирации, геохимические барьеры в ландшафте будут стабильны [86, 87], 
исключается вынос биофилов из почвы, напротив, обеспечивается их возврат в почву.

Поведение воды в почве следует рассматривать с точки зрения термодинамики [88]. При реализации стандартной парадигмы ирригации почва избыточно увлажнена [24]. В диапазоне термодинамического потенциала воды от ПВ 0,0 до НВ -0,03 МПа и ниже вплоть до -0,1 МПа доступность почвенного раствора растениям высокая, что обеспечивает высокий темп нарастания биомассы. При потенциале воды в почве ниже -0,2 МПа устьичный аппарат растения функционирует в режиме регулируемого открытия, сокращая расход воды до уровня ниже потенциальной транспирации. В условиях меньшей по сравнению с НВ влажности аэрация почвы повышается, активизируется биота, переработка вещества в биофильные элементы улучшается. Темп прироста биомассы интенсивнее, чем при высокой влажности почвы. При контролируемом органогенезе для формирования биомассы растению требуется меньшее количество воды, чем полагали ранее. Однако обеспечить требуемый термодинамический потенциал воды в почве в диапазоне -0,2-0,4 МПа посредством традиционного орошения невозможно.

Выполнен эвристический синтез трансцендентальной водной стратегии, исключающий неуправляемые потоки воды в почвенном континууме, обеспечивающий распределения воды и доставку её внутрь почвы в строго контролируемых потребностью биоты и культурных растений микрообъемах в состоянии капиллярной и парообразной воды. Предложена внутрипочвенная импульсная континуальнодискретная парадигма ирригации [24, 89, 90].

Воду впрыскивают в почву (предпочтительно, на фоне внутрипочвенной роторной фрезерной обработки), дозировано распределяют в цилиндре первичного увлажнения на глубине 10-40 см в процессе перемещения шприца по вертикали. Ввиду краткосрочности и щадящего режима процесса гидродинамического воздействия воды механические связи в почве не разрушаются полностью до состояния гранулометрической композиции, и восстанавливаются ввиду механизмов структурной памяти почвы. Влага из цилиндра быстро распределяется капиллярными силами до потенциала -0,2 МПа в цилиндре почвы диаметром 3-4 см на глубине 10-60 см. Почвенный континуум, не подвергшийся непосредственному увлажнению, образует прочный механический каркас. Растения питаются качественным концентрированным почвенным раствором - и не откачивают избыточную воду, как при обычном поливе. Расход воды на ирригацию меньше, чем при традиционном поливе в 5-20 раз. Достигается многократная экономия энергии и ресурсов - в 10-30 раз. Геохимические барьеры в почве, почвообразующей породе и ландшафте при относительно низкой влажности характеризуются как стабильные (ввиду ассоциации ионов в почвенном растворе) [86, 87]. Исключены потери воды и неблагоприятные результаты её неконтролируемого избыточного воздействия на ландшафт, почву и её физико-химические свойства.

Сказанное позволяет вести речь о принципиально новой мировой водной стратегии, обеспечивающей возможность формировать новый устойчивый вектор эволюции биосферы, новых специализированных системах опреснения для осуществления рациональной ирригации.

\section{в) РЕЦИКЛИНГ ОТХОДОВ}

В рамках индустриальной технологической платформы с отходами обращаются по принципу «быстрее от них избавиться». Стихийнобиологический эгоцентризм работоспособен только в дикой природе, причем и там баланс живого и косного вещества квазистационарный, либо зыбкий. Опасно неконтролируемое перераспределение вещества в действующих системах утилизации твердых отходов посредством их сосредоточенного открытого хранения, захоронения, размещения в почве, в системах частичной очистки и утилизация жидких бытовых, животноводческих, технических стоков, обусловливающих эвтрофикацию водных систем.

Прямое сжигание органического вещества обусловливает образование пыли, особо опасных веществ, их перенос в составе выбросов ГРЭС, ТЭЦ, мусоросжигательных заводов даже при использовании дожигания. Разрастаются хвостохранилища, которые являются источником опасного эолового материала [91], загрязняются грунтовые воды и Мировой океан [92], страдает рекреационный облик ландшафта, под захоронения и свалки отводят высококачественные плодородные земли [93], вещество отчуждается из биосферного процесса. Грунтовые экраны, геополотно, залужение, облесение отвалов, терриконов, хвостохранилищ уводят от реального решения проблемы.

Устаревшие технологии утилизации навоза, вместо возврата в почву органического вещества, обогащают атмосферу Земли парниковыми газами. Применяют технологии внесения жидких отходов в почву под нож горизонтального пассивного рыхлителя, на её поверхность и даже дождеванием [94-106]. Сброс отходов в гидросистемы ухудшает их качество, при этом теряется вещество, из которого может быть получен новый биологический продукт [107, 108]. 


\begin{tabular}{l|lr|ll|ll} 
& ISRA (India) & $=\mathbf{1 . 3 4 4}$ & SIS (USA) & $=\mathbf{0 . 9 1 2}$ & ICV (Poland) & $=\mathbf{6 . 6 3 0}$ \\
Impact Factor: & ISI (Dubai, UAE) & $=\mathbf{0 . 8 2 9}$ & PUHL (Russia) & $=\mathbf{0 . 2 3 4}$ & PIF (India) & $=\mathbf{1 . 9 4 0}$ \\
& GIF (Australia) & $\mathbf{0 . 5 6 4}$ & ESJI (KZ) & $=\mathbf{1 . 0 4 2}$ & IBI (India) & $\mathbf{4 . 2 6 0}$
\end{tabular}

Кроме непосредственной опасности уничтожения человеком собственной среды обитания, вплоть до неблагоприятных климатических последствий [102, 109], другая опасность - это недооценка инновационных технических решений в сфере утилизации, рециклинга отходов и безотходных технологий [110]. Назрело понимание выдающейся роли вещества Земли, которому нет замены. Его следует максимально возвращать в почвенный технологический процесс. При этом почва получает вектор эволюции, ориентированный на устойчивое производство дополнительной экологически чистой продукции.

Во многом ситуация с рециклингом отходов обусловлена тем, что исчерпаны возможности современной агротехники и ирригации. Само возникновение биотехнологии, особенно в части применения её возможностей, касающихся производства продовольствия и сырья, следствие безуспешности продолжения имитации природы в стандартной агротехнике и ирригации.

Имеются успехи биотехнологии в переработке и использовании отходов жизнедеятельности в биогаз, щелочном гидролизе, пиролизе, производстве и использовании биочара (обугленные органические остатки) [111], вермикультуре, инсектокультуре [112]. Но биотехнология воспроизводит только часть цикла биосферы, зачастую выпадают такие фазы, как: переработка биологического материала в почве; питание растений; биологический секвестр избыточного атмосферного углерода и продуцирование кислорода; сохранение почвы и биосферы. Каждая из систем утилизации отходов требует завершения, поскольку производит собственные отходы.

Побочные продукты биотехнологии, в том числе, и после прямого разделения бытового мусора [113, 114], можно вносить в почву, превращая в доступные растениям формы, обеспечивая условия жизнедеятельности сапротрофов и некротрофов.

Внесение минерального и органического вещества, в том числе отходов в почву [115], практикуют в старой парадигме её обработки при крошении и перемешивании блоков почвы 50-150 мм. Однако при такой обработке обеспечивается слабый очаговый контакт внесенного вещества с почвенной массой.

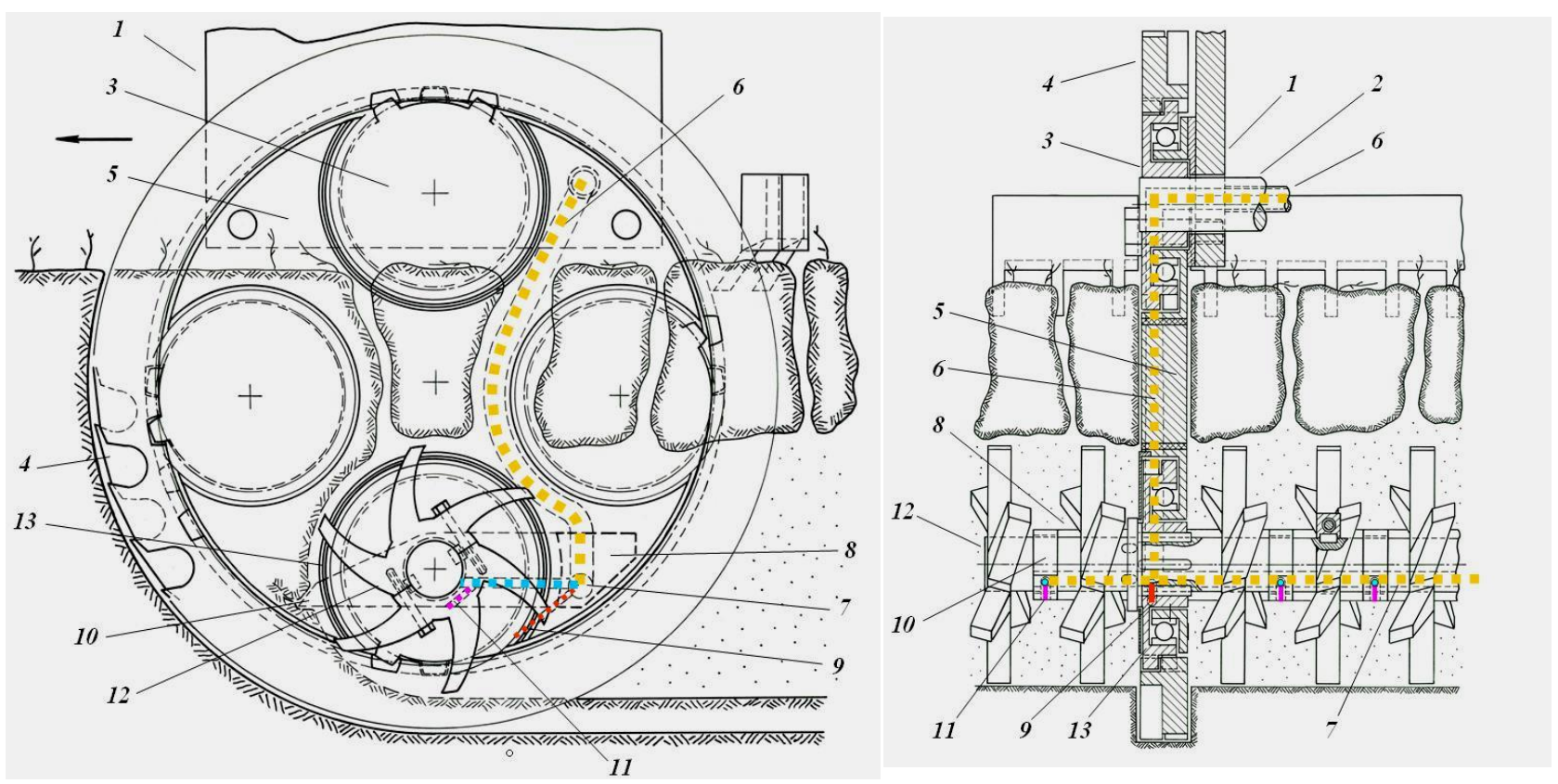

\section{Рисунок 1 - Устройство для внесения вещества в процессе фрезерного внутрипочвенного рыхления.}

Практически все минеральные и органические отходы эффективны при внесении в почву в качестве мелиорантов, структоров, разрыхлителей, источников макро- и микроэлементов [116-118]; опасные вещества в почве инактивируются, либо нейтрализуются. Но для этого должно быть обеспечено миксирование дисперсной системы почвы и вносимого материала [25].

Разработан рециклинг вещества внутри почвы с длительным почвенно-мелиоративным, агрономическим, экологическим и экономическим эффектами путем внесения в жидкой, пастообразной, сыпучей форме фракций 1-3 мм; в процессе фрезерования внутреннего

ISPC Global Science, 
слоя почвы (20-50 см) желательный размер фракций - 1-20 мм (рис.) [119, 120].

Устройство имеет раму 1, вал привода 2, ведущую шестерню 3, кольцевой щелерез 4. По выполненному в диске 5 каналу 6 вещество подают в канал 7 для смазки деталей привода и в канал 8 в рампе 9, откуда оно через рыхлящие пальцы 10 по каналам 11 поступает в почву. Фрезерный рыхлитель 12 получает механический привод от кольцевого щелереза 4 через ведомую шестерню 13.

Фрезерный рыхлитель 12 обрабатывает почву, измельчая, разрыхляя и равномерно перемешивая её с вносимым веществом. Фрезерное внутрипочвенное рыхление улучшает условия развития ризосферы, уменьшает затраты энергии и вещества на создание единицы биологической продукции. Именно поэтому данный способ обеспечивает утилизацию любых органических отходов с высоким биологическим эффектом.

Например, известно, что биологическая эффективность навоза в 3 раза выше, если он внесен внутрь почвы, а не запахан с поверхности, как это принято в стандартных системах земледелия [44]. То же в отношении отходов пищевых производств, продуктов пиролиза, биочара. В новой дисперсной системе почвы минимизирован неконтролируемый перенос вещества, усилены геохимические барьеры [121126], созданы предпосылки высокой биологической продуктивности [127-136], обеспечивается здоровье почвы [137], не нарушается ландшафт [138]. Возможен также синтез вещества внутри почвы [139].

Важной проблемой является утилизация опасных биологических отходов. Если их утилизировать на поверхности почвы, и даже на специальных полигонах, сохраняется высокая вероятность распространения патогенных микроорганизмов, неконтролируемого синтеза и миграции опасных веществ. Если утилизировать биологические, в том числе, боенские отходы по новой технологии, то не только исключены негативные последствия, но и существенно повышается плодородие почвы [25, 26, 140, 141]. При этом нарушаются трофические цепи развития и элиминируются патогенные и фитопатогенные геобионты благодаря действию микроорганизмов-супрессоров.

$$
\text { г) ФЕРТИГАЦИЯ }
$$

Биогеосистемотехника

обеспечивает интеграцию технологий утилизации бытовых, животноводческих, технических и других веществ путем удобрительной ирригации фертигации. Внутрипочвенная импульсная континуально-дискретная система внесения вещества в жидком виде или в виде пульпы продолжение системы полива. Она обеспечивает подачу вещества внутрь цилиндра почвы диаметром 3-4 см на глубине 10-60 см, оптимум питания и водопотребления растений [142], позволяет удобрять почву, обеспечивать экологическую, ветеринарную и медицинскую безопасность посредством утилизации внутри почвы любых веществ с биологическим эффектом повышения плодородия и увлажнения, минимизации загрязнения наземных и водных систем.

В рамках новой парадигмы ирригации любые отходы могут быть экологически безопасно локализованы внутри почвы в жидком или пастообразном виде. Причем без опасности неуправляемого распространения, поскольку подача воды или пульпы в почву ведется не в виде потока на её поверхность, как при стандартной утилизации стоков, а строго дозировано в каждый изолированный микрообъем дисперсной системы почвы.

Высокий биологический эффект одновременного орошения и питания растений исключает эвтрофирование водных систем [143]. Нет выноса вещества из педосферы - все внесенное в почву вещество ассимилируется геобионтами и растениями, в итоге образуется безвредные вещества (гумус, биофилы) и вода. Это позволяет усилить биологические функции почвы [144-146], уменьшить опасность загрязнения биосферы, исключить негативное влияние на будущие поколения человека и животных [147]. Большинство веществ, представляющих опасность для высших организмов, для геобионтов гораздо менее опасны [148, 149]. Утилизация изначально вредного вещества обеспечивается на 100\%.

Приоритетные условия развития растений позволяют ослабить транспортирующую способность приземного воздушного потока, преодолеть самый быстрый и эффективный в отношении контаминации биосферы путь распространения загрязнений - эоловый [150, 151].

Равномерное

рассредоточение загрязняющих веществ в компоненте биосферы внутрипочвенной дисперсной системе оказывает благотворное влияние на развитие растений. Нормативные уровни элементов и соединений в почве (ПДК) даны в расчёте на килограмм массы $[132,135,152-157]$, и это повышает неопределённость и уровень результирующего концентрированного загрязнения. Например, загрязнение, локализованное в 0-2 см слое почвы, особенно опасно для молодых растений, а также с точки зрения высокой вероятности эолового или гидрологического переноса и последующего спонтанного сосредоточения в зоне ослабления транспортирующей способности воздушного или 
водного потока. Однако то же количество поллютанта, но рассредоточенного в 30-60 см слое почвы, представляет собой иную систему: а) распределение загрязняющего вещества здесь контролируемое, а потому безопасно; б) исключен эоловый транспорт опасных веществ; в) исключена опасность загрязнения наиболее чувствительных молодых растений; г) усиливается функционирование геохимических и биологических барьеров, препятствующих поступлению поллютанта в растение; д) расчетный уровень загрязнения по сравнению со слоем 0-2 см в слое почвы 30-60 см номинально в 15 раз меньше, но нелинейный экологический эффект значительно превышает эту величину.

При внутрипочвенном импульсном континуально-дискретном поливе или фертигации средняя влажность почвы невысока, невелика растворимость опасных для растений соединений, содержащиеся в сырье, отходах, удобрениях [121, 158, 159], интенсивны ассоциация и комплексообразование ионов, потому эффективно функционирует биогеохимический барьер «почва-ризосфера» [160].

\section{д) МНОГОЛЕТНИЕ НАСАЖДЕНИЯ}

Биогеосистемотехнический подход применим к садоводству, виноградарству, созданию озеленительных древеснокустарниковых насаждений [161]. Культуры лучше приживаются, быстрее накапливают фитомассу, обеспечивают высокую продуктивность, формируют привлекательный габитус, срок жизни насаждения увеличивается. Если насаждение ориентировано на получение товарной продукции, то её урожайность будет существенно выше за счёт управления органогенезом агрокультуры. При этом обеспечиваются повышенные экономический, экологический и рекреационный эффекты.

е) БИОЛОГИЧЕСКИЙ ПРОДУКТ

Биогеосистемотехника позволяет сократить количество питательных веществ и особенно воды, требуемой на создание единицы биопродукции. Это достигается за счёт того, что растения тратят меньше энергии на продвижение корневой системы вглубь почвы, на транспирацию избыточной воды при переувлажнении или, наоборот, на извлечение воды из сухой почвы. Если в порядке межгосударственного взаимодействия реализовать программы размещения отходов на бесплодных территориях Земли на основе технологий биогеосистемотехники, то это позволит не только превратить отходы в новые ресурсы и производительную силу, создав новые почвы, но и предотвратить проблему голода [18].
При этом будут существенно улучшены условия жизни на планете.

\section{ж) СЕКВЕСТР УГЛЕРОДА}

Секвестр углерода в общепринятой упрощенной постановке как удаление углерода из атмосферы является ложной задачей. В действительности, секвестр $\mathrm{CO}_{2}$ из атмосферы Земли за прошедшие геологические эпохи с точки зрения определённости и устойчивости биосферы и климата оказался избыточным. Неопределенность цикла углерода на Земле обусловлена опасным для биосферы стоком углерода из почвы в зону аэрации, где он исключается из современного биологического процесса [162].

Отрицательное влияние на биосферу оказывает не только водяной пар и углекислый газ, но и уменьшение ионизации воздуха биологически активным кислородом фотосинтеза. Именно потому всё большая опасность исходит от метана, который как причина парникового эффекта гораздо опаснее углекислого газа $[163,164]$.

В море Лаптевых и Восточносибирском море выделяется 50\% глобального стока метана в атмосферу Земли $[165,166]$. Поэтому вместо торговли квотами выбросов углерода в атмосферу России в рамках Киотского протокола и будущих подобных соглашений придётся нести существенные дополнительные расходы.

Секвестр парниковых газов надо осуществлять в биосфере (фитосфере!), обеспечивая ассимиляцию углерода живым веществом растений $[167,168]$. Кроме экологического эффекта, это даст больше продовольствия, сырья, биотоплива. Ископаемые углеводороды после сжигания будут экологически безопасно вовлекаться в современный биогеохимический цикл углерода.

$$
\text { 3) КЛИМАТ }
$$

Исследования последних десятилетий констатируют возрастающую неопределённость климата и его составляющих, необходимость мониторинга и более надёжного прогнозирования циклов климата [169-171]. Существует множество его моделей, отмечают их неустойчивость из-за антропогенного фактора динамики [172]. Ввиду того что модели нестабильны, предметом интереса во многом является климат прошлого как база для климатической экстраполяции на перспективу [173-175].

Неопределённость климата следует контролировать ввиду попыток управлять им интенсивными техногенными факторами [176179]. Специалисты в области климатической инженерии для преобразования климата предлагают настолько экзотические способы, что 
они сами по себе представляют серьёзную опасность для климата Земли $[27,180]$.

Важнейшим результатом применения технологий биогеосистемотехники будет преодоление флуктуаций климата Земли за счёт новых возможностей управления его драйверами. Биогеосистемотехника позволяет перейти от управления климатическими параметрами, попыток воздействовать на климат методами климатической инженерии, к управлению драйверами климата через биосферу [27]. Возможны некоторые новые подходы к стабилизации климатических процессов на Земле:

$\checkmark$ изменение потоков вещества в биосфере;

$\checkmark$ увеличение биологической ёмкости дисперсной системы почвы;

$\checkmark$ управление расходом воды на единицу биологической продукции и сокращение эмиссии водяного пара как основного парникового газа [181];

$\checkmark$ увеличение биологической фазы вещества (углерода и др.);

$\checkmark$ увеличение экспансии биосферы, в том числе в те области, где без применения методов биогеосистемотехники биосферные функции невозможно реализовать;

$\checkmark$ секвестр углекислого газа, в том числе, антропогенного происхождения;

$\checkmark$ увеличение биомассы, как демпфера климата;

$\checkmark$ уменьшение содержания углекислого газа в атмосфере;

$\checkmark$ увеличение содержания атмосферного кислорода и ионизации воздуха за счет фотосинтеза;

$\checkmark$ увеличение нормы окисления метана за счет ионизации воздуха;

$\checkmark$ управление альбедо;

$\checkmark$ неограниченный энергетический потенциал за счет использования фотосинтеза для получения биотоплива, биогаза из дополнительной биологической продукции, включая использование продуктов окисления углеводородов в качестве дополнительного источника вещества для расширения биологического процесса и увеличения нормы биологической продукции на Земле;

$\checkmark$ упреждающее управление обратной связью в климатической системе Земли путем варьирования драйверами климата.

\section{и) РОБОТОТЕХНИКА}

Биогеосистемотехника обеспечивает новый, беспрецедентный уровень встраивания технических решений в биосферу. Причем все эти решения могут быть реализованы на уровне робототехники, что обеспечит экономию материальных и энергетических ресурсов во много раз.
Перспективны роботизированные системы управления веществом, водой в дисперсной системе почвы, технологиями создания и сбора биологических продуктов. Это обеспечит мультипликативные эффекты развития механотроники, робототехники, материаловедения, информационных технологий позиционирования объектов и явится составляющей новой индустриализации, позволит сформировать престижную занятость населения в наукоемкой сфере труда важнейшие характеристики технологий ноосферы XXI века [182].

\section{ЗАКЛЮЧЕНИЕ}

Биогеосистемотехника - это результат применения квалифицированной эвристической интуиции, превосходящей возможности синергетики. Управление вещественным составом компонентов биосферы и элементов ландшафта позволяет повысить биопродуктивность, увеличить размер территорий, где этот агропродукт может быть получен; утилизировать природные и техногенные парниковые газы посредством оптимизации биогеохимических циклов. Так, интенсификация фотосинтеза позволит производить больше ионизированного кислорода, обеспечить биологический обратимый секвестр углерода из атмосферы в биологическую продукцию; окислять метан и сероводород; производить дополнительное продовольствие, сырье, биотопливо; повышать ресурсный потенциал и технологическую емкость биосферы, управлять качеством атмосферы. В итоге достигается декаплинг - снижение затрат на выполнение экологичных технологий в сравнении с традиционно используемыми.

Биогеосистемотехника обеспечивает: а) оздоровление и ремедиацию почв, ландшафтов и водных систем; б) долгосрочное улучшение плодородия и здоровья почв; в) рециклинг отходов; г) усиление биосферного цикла углерода, азота, воды и других элементов посредством усиления фотосинтеза, увеличение прироста органического вещества, кислорода, свободных ионов, и как следствие биологического разнообразия биосферы; д) безопасность и качество экосферы, новый вектор устойчивой, сбалансированной эволюции наземных и водных экосистем; е) устойчивость биосферы; ж) стабильно демпфированный климат Земли; 3) сокращение территории пустынь и увеличение площади суши, пригодной для проживания людей и агропроизводства; и) ускоренное экологичное технологическое развитие; к) прирост нормативно-безопасной продовольственной, кормовой и сырьевой базы; л) прирост экологически чистого биотоплива и биогаза; м) ускоренное расширенное 
воспроизводство возобновимых энергоресурсов; н) развитие роботизации; о) увеличение занятости населения в наукоемкой экологичной производственной сфере; п) декаплинг; р) повышение качества жизни социума. Появляется реальная возможность смягчить противостояние Человечества, Техносферы и Биосферы. Достигается управляемое контролируемое антропогенное возмущение биосферы с целью получения её нового трансцендентального экологически устойчивого состояния, повышение рекреационного качества биосферы и гармония Ноосферы.

Биогеосистемотехника для России возможность позитивно влиять на долгосрочные процессы гармоничного бескризисного развития мира в высококачественной, устойчивой биосфере на трансцендентальной технологической платформе ноосферы. Принятие биогеосистемотехники как национального инфраструктурного инновационного проекта, имеющего мировой приоритет, позволит дать новый импульс развитию социума, сформировать привлекательный образ нашей страны как державы, способной обеспечить гармоничное развитие мира на основе природоподобных технологий, оптимизировать процесс эволюции биосферы и социосферы в ноосферу [8, 29, 183185].

\section{References:}

1. Glazko Valery I., Glazko Tatiana T (2015) Conflicts of Biosphere and Agroecosystems // International Journal of Environmental Problems. 2015. Vol. (1). Is. 1. pp. 4-16. DOI: 10.13187/ijep.2015.1.4

2. Vladimir G. Sister, Igor' S. Tartakovsky, Andrey N. Tsedilin, Nina V. Vorobeva (2014) Transformation of Components of Human Environment Under Anthropogenic Impact // Biogeosystem Technique. 2014. Vol. (2). No 2. pp. 174-181. DOI: $10.13187 /$ bgt.2014.2.174

3. Sposito G (2013) Green water and global food security // Vadose Zone Journal.12. 2013: doi:10.2136/vzj2013.02.0041.

4. (2014) Giuseppe Di Capua and Silvia Peppoloni Geoethics and geoscientists: some ongoing initiatives // Geophysical Research Abstracts. EGU General Assembly. Vienna, 2014. DOI Vol. 16. EGU2014-2263

5. Ivanitskaya Lidia V, Sokolov Mikhail S., Glazko Valery I. (2015) No-alternative and the Factors of Social and Environmental Coevolution of the Biosphere into the Noosphere (the Development of the Biosphere Ideas of Vernadsky) // Biogeosystem Technique. 2015. Vol. (3). Is. 1. pp. 29-49. DOI: 10.13187/bgt.2015.3.29 www.ejournal19.com

6. (2016) International Commission Calls for 'Paradigm Shift' in Agriculture. Available: www.worldwatch.org/node/5712 (Accessed: 10.04.2016).

7. Derrel M. (2016) Changing Paradigm in Irrigation Water Management // Biological Systems Engineering. University of Nebraska. Lincoln Extention. Available: http://www.heartlandwq.iastate.edu/NR/rdonlyr es/22B951AE-57DC-4482-80BC-
E49105AD053E/116921/Martin_ChangingPara digmforIrrigatedWater.pdf (Accessed: 10.04.2016).

8. Putin VV (2015) Vystuplenie na zasedanii general'noy Assamblei OON. 28 september 2015. Available: http://www.1tv.ru/news/polit/293099 (Accessed: 10.04.2016).

9. Mitcham C (1994) Thinking through Technology: The Path between Engineering and Philosophy. University of Chicago Press: 1994. ISBN 978-0-226-53198-4

10. (2016) Sustainable development Available: http://en.wikipedia.org/wiki/Sustainable develo pment (Accessed: 10.04.2016).

11. (2016) Converging Technologies for Improving Human Performance. Available: https://en.wikipedia.org/wiki/Converging_Tech nologies_for_Improving_Human_Performance (Accessed: 10.04.2016).

12. (2016) Green Economy. United Nation Environment Programme. Available: http://www.unep.org/greeneconomy/ (Accessed: 10.04.2016).

13. Koval'chuk MV, Naraykin OS, Yatsishina EB (2013) Konvergentsiya nauk i tekhnologiy novyy etap nauchno-tekhnicheskogo razvitiya // Voprosy filosofii. 2013. № 3. pp.3-11. Available:

http://vphil.ru/index.php?option=com content\& $\underline{\text { task=view } \& \text { id }=716 \& \text { Itemid }=52 \quad \text { (Accessed: }}$ 10.04.2016).

14. Kotlyakov VM, Tishkov AA, Klyuev NN, Borodina TL, Glezer O.B., Mokhov I.I., Khon V.Ch., Chernokul'skiy A.V., Zolotokrylin A.N., Cherenkova E.A., Titkova T.B., Vinogradova V.V., Mikhaylov A.Yu., Rumyantsev V.A., 


\begin{tabular}{|c|c|c|c|c|c|c|}
\hline Impact Factor: & $\begin{array}{l}\text { ISRA (India) } \\
\text { ISI (Dubai, UAF } \\
\text { GIF (Australia) } \\
\text { JIF }\end{array}$ & $\begin{array}{l}=1.344 \\
=0.829 \\
=0.564 \\
=1.500\end{array}$ & $\begin{array}{l}\text { SIS (USA) } \\
\text { PИНЦ (Russia) } \\
\text { ESJI (KZ) } \\
\text { SJIF (Morocco) }\end{array}$ & $\begin{array}{l}=0.912 \\
=0.234 \\
=1.042 \\
=\mathbf{2 . 0 3 1}\end{array}$ & $\begin{array}{l}\text { ICV (Poland) } \\
\text { PIF (India) } \\
\text { IBI (India) }\end{array}$ & $\begin{array}{l}=6.630 \\
=1.940 \\
=4.260\end{array}$ \\
\hline
\end{tabular}

Koronkevich N.I., Ptichnikov A.V., Voropaev A.I., Bulgakova V.A., Mokrushina L.S., Vaysfel'd M.A., et al. (2014) Strategicheskie resursy i usloviya ustoychivogo razvitiya Rossiyskoy Federatsii i ee regionov / Kratkie itogi realizatsii Programmy fundamental'nykh issledovaniy Otdeleniya nauk o Zemle RAN №13. «Geograficheskie osnovy ustoychivogo razvitiya Rossiyskoy Federatsii i ee regionov» v 2012-2014 gg. / Pod redaktsiey akademika V.M. Kotlyakova i professora A.A. Tishkova. M.: Institut geografii RAN. 2014. 166 s. ISBN 978-5-89658-042-3.

Available:

http://www.twirpx.com/file/1657006/

(Accessed: 10.04.2016).

15. Glaz'ev SY (2013) O politike operezhayushchego razvitiya $\mathrm{v}$ usloviyakh smeny tekhnologicheskikh ukladov // Vestnik RAEN. 2013. T. 13. № 1. pp. 29-35.

16. Fursov AI (2016) Razvitie (3:30-4:30) Available:

https://www.youtube.com/watch?v=KQny249w pbo (Accessed: 10.04.2016).

17. Cleveland C (2014) Sustainability: A canvas of perspectives // 248th ACS National Meeting \& Exposition. 13TH IUPAC International Congress of Pesticide Chemistry. Crop, Environment, and Public Health Protection. Technologies for a Changing World. Cosponsored by IUPAC and ACS-AGRO. August 10-14, 2014. San Francisco, California, USA. Abstracts. AGRO 143. pp. 7.

18. Arnold T (2014) Policy considerations for food and nutrition security towards $2050 / /$ 248th ACS National Meeting \& Exposition. 13TH IUPAC International Congress of Pesticide Chemistry. Crop, Environment, and Public Health Protection. Technologies for a Changing World. Co-sponsored by IUPAC and ACSAGRO. August 10-14, 2014. San Francisco, California, USA. Abstracts. AGRO 143. pp. 217

19. Kalinichenko VP, Lyakhov VP, Yusupov VU, Khalilov RR (2015) Biogeosistemotekhnika kak novaya osnova sinteza idei i atributov natsional'noy bezopasnosti v 21 veke // Gosudarstvennoe i munitsipal'noe upravlenie. Uchenye zapiski SKAGS. 2015. №3. pp. 144149.

20. Moskalenko AP, Kalinichenko VP, Ovchinnikov VN, Moskalenko SA, Gubachev VA (2013) Biogeosistemotekhnika - osnova praktiki ekologicheskoy politiki i ekologicheskoy ekonomiki // Ekonomika i predprinimatel'stvo. 2013. №12-3 (41-3). pp. 160-165.

21. (2016) Global'naya biosfera Available: http://en.wikipedia.org/wiki/File:Seawifsglobal _biosphere.jpg (Accessed: 10.04.2016).
22. Byerlee Derek, Alain de Janvry, and Elisabeth Sadoulet (2009) Agriculture for Development: Toward a New Paradigm / // Annual Review of Resource Economics. Vol. 1: 15-31 (Volume publication date May 2009). First published online as a Review in Advance on May 21, 2009

DOI: 10.1146/annurev.resource.050708.144239

23. Walter V. Reid, et al. (2005) Millennium Ecosystem Assessment. Ecosystems and Human Well-being - Synthesis. 2005. 155 p. ISBN: 1-59726-040-1.

24. Kalinichenko V (2014) Biogeosystem Technique as a base of the new world water strategy // Biogeosystem Technique. 2014. № 2 (2). 100-124. pp. DOI: 10.13187/bgt.2014.2.100

25. Kalinichenko Valery P (2015) Biogeosystem Technique as a Paradigm of Non-waste Technology in the Biosphere // Biogeosystem Technique, 2015, Vol.(3), Is. 1, pp. 4-28. DOI: 10.13187/bgt.2015.3.4

26. Kalinichenko Valery P., Starcev Viktor F. (2015) Recycling of Poultry Litter by Method of Biogeosystem Technique // International Journal of Environmental Problems, 2015, Vol. (1), Is. 1 , pp. 17-48. DOI: 10.13187/ijep.2015.1.17

27. Kalinichenko Valery P. (2015) Biogeosystem technique as the method for Earth's climate stabilizing // Biogeosystem Technique, 2015, Vol.(4), Is. 2, pp. 104-137. DOI: 10.13187/bgt.2015.4.104

28. (2016)

Available: https://en.wikipedia.org/wiki/Climate_engineeri ng (Accessed: 10.04.2016).

29. Vernadskiy VI (1926) Biosfera. L.: Nauchnoe khim.-tekhn. izd., 1926.

30. Viner Duglas R (2000) Kul't Vernadskogo i noosfera // V. I. Vernadskiy: pro et contra. SPb., 2000.

31. (2016) Programma «Chistyy Don» Available: http://molotro.ru/news/v-rostovskoy-oblastibudet-realizovan-ekologicheskiy-proektprogrammy-chistyy-don 10.04.2016).

32. (2016) Zavod shirokozakhvatnoy dozhdeval'noy tekhniki Available: http://rostov.dkvartal.ru/news/valmontindustries-inc-investiruet-360-mln-rub-v-zavodv-rostovskoj-oblasti-236692938 http://www.valley-ru.com/page.aspx?id=1914 (Accessed: 10.04.2016).

33. (2016) Razdel'nyy sbor musora. SCHÄFER Available: $\quad$ http://www.ssi-schaefer.ru (Accessed: 10.04.2016).

34. (2016) Dominator 600 kul'tivator. Available: www.duport.nl (Accessed: 10.04.2016). 
35. Gryaznoy FD, Pyasetskiy DA (1972) Avtorskoe svidetel'stvo SU 493202 A1. MPK5 A01C23/02, A01G29/00. Mashina dlya rykhleniya i podkormki zadernennykh pochv. Zayavka №1844115 ot 09.11.1972. Opublikovano 30.11.1975.

36. Alekseev AV (2014) Gosudarstvennye programmy: real'nyy ili nominal'nyy instrument upravleniya ekonomikoy? // Ekonomist. 2014. №6. pp. 20-27.

37. Musin MM, Gubanov SS (2013) Novaya industrializatsiya // Sverkhnovaya real'nost'. 2013. vyp. 6. pp. 20-27.

38. Kalinitchenko VP, Batukaev AA, Zarmaev AA, Minkina TM, Starcev VF, Dikaev ZS, Magomadov AS, Jusupov VU (2014) Biogeosystem technique as a contribution to global food sustainability // 248th ACS National Meeting \& Exposition. 13TH IUPAC International Congress of Pesticide Chemistry. Crop, Environment, and Public Health Protection. Technologies for a Changing World. Co-sponsored by IUPAC and ACS-AGRO. August 10-14, 2014. San Francisco, California, USA. Abstracts. AGRO 143. pp. 37.

39. Kalinitchenko VP, Batukaev AA, Zinchenko VE, Zarmaev AA, Magomadov AS, Chernenko VV, Startsev VF, Bakoev SU, Dikaev ZS (2014) Biogeosystem technique as a method to overcome the Biological and Environmental Hazards of modern Agricultural, Irrigational and Technological Activities // Geophysical Research Abstracts. EGU General Assembly. Vienna, 2014. DOI: Vol. 16. EGU2014-17015.

40. Korost DV, Gerke KM, Skvortsova EB (2012) Issledovanie struktury pochv s pomoshch'yu rentgenovskoy tomografii: primery rossiyskikh pochv i perspektivy metoda / Materialy dokladov VI s"ezda Obshchestva pochvovedov im. V.V. Dokuchaeva. Vserossiyskaya $s$ mezhdunarodnym uchastiem nauchnaya konferentsiya «Pochvy Rossii: sovremennoe sostoyanie, perspektivy izucheniya i ispol'zovaniya (Petrozavodsk-Moskva, 13-18 avgusta 2012 g.). Petrozavodsk: Karel'skiy nauchnyy tsentr RAN, 2012.

41. Lebedeva (Verba) MP (2012) Prostranstvennaya izmenchivost' mikrostroeniya pochv aridnykh territoriy / Materialy dokladov VI s"ezda Obshchestva pochvovedov im. V.V. Dokuchaeva. Vserossiyskaya s mezh-dunarodnym uchastiem nauchnaya konferentsiya «Pochvy Rossii: sovremennoe sostoyanie, perspektivy izucheniya i ispol'zovaniya (PetrozavodskMoskva, 13-18 avgusta 2012 g.). Petrozavodsk: Karel'skiy nauchnyy tsentr RAN, 2012
42. Goryachkin VP (1965) Sobranie sochineniy. M.: Izd-vo Kolos, 1965. t. 1.720 p. t. 2.459 p. t. $3.384 \mathrm{p}$.

43. Dospekhov BA (1987) Praktikum po zemledeliyu. 2-e izdanie. M.: Agrpromizdat, 1987. 383 p.

44. Sdobnikov SS (1994) Pakhat' ili ne pakhat'? (novoe v obrabotke i udobrenii poley). M., 1994. $286 \mathrm{p}$.

45. Moberly PK (1972) Deep tillage investigations on five soil types of the South Afican sugarbelt // Proceedings of The South African Sugar Technologists' Association. 1972. pp. 205-210.

46. (2016) Great Plains: Vertical Tillage Principles Available:

http://www.youtube.com/watch?v=EwG4hqtn0 VA (Accessed: 10.04.2016).

47. (2008) Polevoy opredelitel' pochv. M.: Pochvennyy in-t im. V.V. Dokuchaeva, 2008. 182 p. Available: http://soils.narod.ru/download/field_guide_int.p df (Accessed: 10.04.2016).

48. Vlasenko VP (2012) Gidrometamorfizm pochv Severo-Zapadnogo Kavkaza pri ikh sel'skokhozyaystvennom ispol'zovanii. Avtoref dis ... dokt s.-kh. nauk. Krasnodar. 2012

49. Sushko KS, Bespalova LA, Bespalova EV (2015) Issledovanie transformatsiy prirodnoantropogennykh landshaftov sukhikh stepey doliny Manycha // Estestvennye i tekhnicheskie nauki. 2015. № 6 (84). pp. 225-229.

50. Vasilenko VN, Zinchenko VE, Kalinichenko VP (2005) Upravlenie plodorodiem pochv Yuzhnogo federal'nogo okruga Rossii. Chast' 1 // Izvestiya vysshikh uchebnykh zavedeniy. Severo-Kavkazskiy region. Estestvennye nauki. 2005. №2. pp. 78-83.

51. Vasilenko VN, Zinchenko VE, Kalinichenko VP (2005) Upravlenie plodorodiem pochv Yuzhnogo federal'nogo okruga Rossii. Chast' 2 // Izvestiya vysshikh uchebnykh zavedeniy. Severo-Kavkazskiy region. Estestvennye nauki. 2005. №3. pp. 75-79.

52. Moiseeva TS, Bezuglova OS, Morozov IV (2011) Opredelenie plotnosti tverdoy fazy pochvy V chernozeme obyknovennom // Fundamental'nye issledovaniya. 2011. № 11-1. pp. 174-177.

53. Bezuglova Olga S., Anastasiya E. Shimko (2014) The Use of Lignite and Compost-based Sewage Sludge as a Fertilizer and Soil Ameliorants // Biogeosystem Technique. 2014. Vol.(1). № $1 . \quad$ pp. 41-49. DOI: 10.13187/bgt.2014.1.41

54. Demkin VA, Borisov AV, Demkina TS, Udal'tsov SN (2012) Evolyutsiya pochv i dinamika klimata stepey yugo-vostoka russkoy ravniny $\mathrm{v}$ epokhi enelita i bronzy (IV-II tys. do 
n.e.) // Izvestiya Rossiyskoy akademii nauk. Seriya geograficheskaya. 2012. №1. pp. 46-57.

55. Maltsev AV, Kalinitchenko VP, Shatokhin SA, Udalov AV (2013) Dynamics of Agrophysical Properties and Humus Content in Chernozem under the Moldboard, Chisel and Surface Systems of Basic Soil Tillage // Russian Agricultural Sciences. 2013. Vol. 39. No. 1. pp. 66-69. (C) Allerton Press, Inc., 2013

56. Khalanskiy VM, Gorbachev IV (2003) Sel'skokhozyaystvennye mashiny. M.: Kolos, 2003. 624 p.

57. (2016) Equipment Comparisons For Deep Plowing Solonetzic Soils. Available: http://www.agriculture.alberta.ca/app21/ministr ypage (Accessed: 10.04.2016).

58. (1977) Protokol vedomstvennykh ispytaniy frezy solontsovoy FS-1,3. Ministerstvo sel'skogo khozyaystva RSFSR. Vsesoyuznyy nauchno-issledovatel'skiy institut mekhanizatsii i elektrifikatsii sel'skogo khozyaystva. Donskoy zonal'nyy nauchno-issledovatel'skiy institut sel'skogo khozyaystva. Donskoy s.-kh in-t. Zernograd, 1977. 14 p.

59. Vakulin AA, Kirillov VV, Kobzarev AI (1972) Obrabotka solontsov rotornym orudiem // Dokl. VASKhNIL. 1972. №2. pp. 41-43.

60. Bok NB, Cheremisinov OA, et al. (1976) Rezul'taty ispytaniy orudiy dlya obrabotki solontsov // Tez. dokl. na Vsesoyuznom nauchno-tekhnicheskom soveshchanii. Rostovna-Donu, 1976. pp. 120-121.

61. (1989) Akt 24-39V...42-89V (90691109069114) Gosudarstvennykh sravnitel'nykh ispytaniy solontsovykh orudiy PYaS-1.4; PYaS-4-35; MSP-2; PS-3-40. SeveroKavkazskaya gosudarstvennaya mashinoispytatel'naya stantsiya. Zernograd. 1989. 21 p.

62. Kalinichenko VP, Sharshak VK, Mironchenko SF, Chernenko VV, Ladan EP, Genev ED, Illarionov VV, Udalov AV, Udalov VV, Kippel' EV (2014) Izmenenie svoystv pochv solontsovogo kompleksa cherez 30 let posle meliorativnykh obrabotok // Pochvovedenie. 2014. №4. pp. 490-506. DOI: $10.7868 / \mathrm{S} 0032180 \mathrm{X} 14040029$

63. Kalinichenko VP (2014) Biogeosystem technique as a problem // Biogeosystem Technique. 2014. № 1 (1). pp. 4-19. DOI: 10.13187/bgt.2014.1.4

64. Kalinichenko VP (2009) Ustroystvo dlya rotatsionnogo vnutripochvennogo rykhleniya. Patent RU №2376737 S1. Patentoobladatel' IPPYuR. Zaregistrirovano v Gosudarstvennom reestre izobreteniy Rossiyskoy Federatsii 27 dekabrya 2009 g. MPK A01V 33/02 (2006.01) A01V 33/02 (2006.01). Zayavka №2008118583/12(021536) ot 08.05.2008.
Opublikovana 27.12.2009. Byul. №36. 8 p.: 2 il.

65. (2005) Rotating cultivator for under-humus soil layer. Geneva. Switzerland. The international Bureau of WIPO. Geneva. Switzerland. Patent cooperation treaty WO 2005/099427 A1. International application: PCT RU/2005/000195. Classification of subject matter: A01V 13/08, 13/16, 49/02. International filing date: 15 April 2005 (15.04.2005). International publication date: 27 October 2005 (27.10.2005). Priority date: 200411156416 April 2004 (16.04.2004) RU. Applicant: Institut Plodorodiya Pochv Uga Rossii (IPPYUR). Izobretatel': V.P. Kalinichenko.

66. (2008) Akt. FGU Severo-Kavkazskaya MIS. 18.02.2008.

67. Kalinichenko VP, Sharshak VK., Ladan EP, Illarionov VV, Genev ED (2014) Tekhnicheskie sredstva vnutripochvennogo rykhleniya $\mathrm{S}$ malym tyagovym soprotivleniem // Vestnik Donskogo gosudarstvennogo tekhnicheskogo universiteta.2014. Volume: 14 issue: 2(77). pp. 151-163. DOI: $10.12737 / 4467$.

68. (2016) Kuhn Gladiator Available: http://www.youtube.com/watch?v=7jDujACA7 n4 (Accessed: 10.04.2016).

69. Kalinichenko VP (2013) Sposob dolgovremennogo upravleniya produktivnost'yu stepnykh biogeosistem. Patent RU №2480980 S1. MPK K1. MPK A01G 7/00 (2006.01) A01V 79/00 (2006.01) A01B 13/14 (2006.01) A01V 33/02 (2006.01). Patentoobladatel': Kalinichenko V.P. Zayavka №2011135858/13(053162) ot 26.08.2011. Opublikovano 10.05.2013. Byul. №13. 15 p.

70. Berezin LV, Saparov AS, Kann VM, Shayakhmetov MR (2013) Tekhnologiya kompleksnoy melioratsii ekosistem Rossii i Kazakhstana. Almaty-Omsk, 2013. 215 p.

71. Berezin LV (2014) New Paradigm of Soil Treatment // Biogeosystem Technique. 2014. Vol.(2), № 2. pp. 133-149. DOI: 10.13187/bgt.2014.2.133 www.ejournal19.com

72. Moskalenko AP, Kalinichenko VP, Moskalenko SA, Gubachev VA (2012) Ekologoekonomicheskie aspekty metodiki obosnovaniya innovatsionnoy tekhnologii obrabotki pochv // Vestnik YuzhnoRossiyskogo gosudarstvennogo tekhnicheskogo universiteta (Novocherkasskogo politekhnicheskogo instituta). Seriya: Sotsial'no-ekonomicheskie nauki. 2012. № 4. pp. 114-123.

73. Agal'tseva NA, Bolgov MV, Spektorman TY, Trubetskova MD, Chub VE (2011) Otsenka gidrologicheskikh kharakteristik $\mathrm{v}$ basseyne Amudar'i v usloviyakh izmeneniya klimata. // 


\begin{tabular}{l|lrl|l|ll} 
& ISRA (India) & $=\mathbf{1 . 3 4 4}$ & SIS (USA) & $=\mathbf{0 . 9 1 2}$ & ICV (Poland) & $=\mathbf{6 . 6 3 0}$ \\
Impact Factor: & ISI (Dubai, UAE) $=\mathbf{0 . 8 2 9}$ & PUHI (Russia) & $=\mathbf{0 . 2 3 4}$ & PIF (India) & $=\mathbf{1 . 9 4 0}$ \\
& GIF (Australia) & $\mathbf{0 . 5 6 4}$ & ESJI (KZ) & $=\mathbf{1 . 0 4 2}$ & IBI (India) & $=\mathbf{4 . 2 6 0}$
\end{tabular}

Meteorologiya i gidrologiya. 2011. № 10. pp. 58-69.

74. (2014) Fitsum Woldemeskel, Ashish Sharma, Bellie Sivakumar, and Raj Mehrotra. Quantifying GCM uncertainty for estimating storage requirements in Australian reservoir // Geophysical Research Abstracts. EGU General Assembly. Vienna, 2014. DOI: Vol. 16. EGU2014-12151.

75. Felix Wiß, Tobias Stacke, and Stefan Hagemann (2014) Statistical analysis of simulated global soil moisture and its memory in an ensemble of CMIP5 general circulation models // Geophysical Research Abstracts. EGU General Assembly 2014. Vienna, 2014. DOI: Vol. 16. EGU2014-14086.

76. Solntseva NG, Kalinichenko VP (2005) Izmenenie plotnosti chernozema obyknovennogo Nizhnego Dona pri razlichnom rezhime uvlazhneniya // Izvestiya vysshikh uchebnykh zavedeniy. Severo-Kavkazskiy region. Estestvennye nauki. 2005. №3. pp. 9194.

77. Benz Kotzen (2014) Novel ideas for maximising dew collection to aid plant establishment to combat desertification and restore degraded dry and arid lands // Geophysical Research Abstracts. EGU General Assembly.Vienna, 2014. DOI: Vol. 16. EGU2014-1481

78. Shelef Oren, Elaine Soloway, and Shimon Rachmilevitch (2014) Introduction and domestication of woody plants for sustainable agriculture in desert areas // Geophysical Research Abstracts. EGU General Assembly.Vienna, 2014. DOI: Vol. 16, EGU2014-11829.

79. Shein EV, Shcheglov DI, Umarova AB, Sokolova IV, Milanovskiy EY (2009) Strukturnoe sostoyanie tekhnozemov i formirovanie $\mathrm{v}$ nikh preimushchestvennykh potokov vlagi // Pochvovedenie. 2009. № 6. pp. 687-695.

80. Dubenok NN (2014) Prioritety nauchnogo obespecheniya razvitiya melioratsii // Izvestiya Timiryazevskoy sel'skokhozyaystvennoy akademii. 2014. № 1. pp. 96-104.

81. (2016) Aral Sea Foundation Available: info@aralsea.org (Accessed: 10.04.2016).

82. Minkin MB, Kalinichenko VP (1981) Intensifikatsiya meliorativnogo protsessa na pochvakh solontsovykh kompleksov posredstvom regulirovaniya gidrologicheskogo rezhima // Pochvovedenie. 1981. №11. pp. 8899.

83. Minkin MB, Kalinichenko VP (1988) Melioratsiya mocharistykh pochv Vostochnogo Donbassa. Pochvovedenie. 1988. №2. pp. 111121.
84. Kalinichenko VP, Minkin MB (1988) Matematicheskoe modelirovanie prostranstvenno neodnorodnykh struktur pochvennogo pokrova // Biologicheskie nauki. 1988. №12. pp. 77-86.

85. Kalinichenko VP, Minkin MB (1993) Transformatsiya struktury pochvennogo pokrova pri irrigatsii // Pochvovedenie. 1993. №1. pp. 70-76.

86. Minkina TM, Endovitskiy AP, Kalinichenko VP, Fedorov YA (2012) Karbonatno-kal'tsievoe ravnovesie v sisteme voda-pochva. Rostov-naDonu: Izd-vo Yuzhnogo federal'nogo universiteta, 2012. $376 \mathrm{p}$.

87. Endovitsky AP, Minkina TM, Kalinichenko VP, Batukaev AA, Dikaev ZS, Sushkova SN (2014) The association of ions in the soil solution of saline soils // American Journal of Agricultural and Biological Sciences 9 (2): 238244, 2014. ISSN: 1557-4989. (C2014 Science Publication. doi:10.3844/ajabssp.2014.238.244 $\begin{array}{llll}\text { Published Online } 9 & \text { (2) } 2014\end{array}$ (http://www.thescipub.com/ajabs.toc )

88. Shein EV (2015) Matematicheskie fizicheski obosnovannye modeli $\mathrm{v}$ pochvovedenii: istoriya razvitiya, sovremennoe sostoyanie problemy i perspektivy (analiticheskiy obzor) // Pochvovedenie. 2015. № 7. pp. 816.

89. Kalinichenko VP (2010) Patent na izobretenie RU №2386243 S1. Sposob vnutripochvennogo impul'snogo diskretnogo poliva rasteniy. MPK A01G 25/06 (2006.01) A01S 23/02 (2006.01). Zayavka №2009102490/12 ot 16.01.09.. Zaregistrirovano v Gosudarstvennom reestre izobreteniy Rossiyskoy Federatsii 20 apr. 2010. Opublikovanj 20.04.2010. Byul. №11. 9 pp. : 4 il.

90. Kalinichenko VP, Minkina TM, Bezuglova OS, Zarmaev AA, Romanov OV, Kim VCD (2013) Kontseptsiya vnutripochvennoy diskretnoy impul'snoy irrigatsii // Prirodoobustroystvo. 2013. №2. pp. 6-11.

91. Mun SA, Larin SA, Glushkov AN (2013) Vliyanie dobychi uglya na zagryaznenie atmosfery i zabolevaemost' rakom legkogo v Kemerovskoy oblasti // Sovremennye problemy nauki i obrazovaniya. 2013. №1. Available: http://www.science-education.ru/107-8406 (Accessed: 10.04.2016).

92. Teri Sforza (2007) New plan replaces sewage sludge fiasco // Orange County Register. March 14, 2007. Updated Aug. 21, 2013 1:17 p.m. Available:

http://www.ocregister.com/news/enertech60484-angeles-process.html (Accessed: 10.04.2016).

93. Rasheed PMA (2011) Sewage network now covers all areas of Dubai // The Gulf Today. January 18, 2011. Available: 
https://web.archive.org/web/20130504074926/h ttp://gulftoday.ae/portal/7643b815-413c-458ab095-0f38be12ce35.aspx

(Accessed: 10.04.2016).

94. Overcash MR, Humenlik FJ, Miner RJ (2000) Livestock Waste Management. Vol. 1. CRC Press, 2000. Corporate Blvd, NW, Boca Raton, F.L.

95. (2016) Biokompleks. Available: http://biokompleks.ru/work/gen/vnesenie/ (Accessed: 10.04.2016).

96. (2016) Utilizatsiya navoza/pometa Available: http://www.eco.sznii.ru/booklet.pdf (Accessed: 10.04.2016).

97. Pote D.H., T.R. Way, P.J.A. Kleinman, P.A. Moore, J.J. Meisinger, K.R. Sistani, L.S. Saporito, A.L. Allen and G.W. Feyereisen (2011) Subsurface Application of Poultry Litter in Pasture and No-Till Soils // Journal of Environmental Quality 2011 40: 2: 402-411 doi:10.2134/jeq2010.0352

98. Sobgayda Natal'ya A., Anzhelika B. Solodkova (2015) Recycling Spent Activated Sludge // International Journal of Environmental Problems. 2015. Vol. (1). Is. 1. pp. 64-74. DOI: 10.13187/ijep.2015.1.64

99. Luo YM, Christie P (1998) Bioavailability of Cupper and Zink in Soils Treated with Alkaline Stabilized Sewage Sluges // Journal of Environmental Quality. 1998. 27: 335-342.

100. Muirhead RA (2015) Farm-Scale Risk-Index for Reducing Fecal Contamination of Surface Waters // Journal of Environmental Quality $2015 \quad 44: \quad$ 1: $\quad 248-255$ doi:10.2134/jeq2014.07.0311

101. Maguire Rory O., Peter J. A. Kleinman and Douglas B. Beegle (2011) Novel Manure Management Technologies in No-Till and Forage Systems: Introduction to the Special Series // Journal of Environmental Quality 2011 40: 2: 287-291 doi:10.2134/jeq2010.0396

102. Angst TE, Six J, Reay DS and Sohi SP (2014) Impact of pine chip biochar on trace greenhouse gas emissions and soil nutrient dynamics in an annual ryegrass system in California // Agroecosystems and the Environment. 2014. Volume 191. 15 June 2014. pp. 17-26 http://dx.doi.org/10.1016/j.agee.2014.03.009

103. Rhodes Eric R., Laura A. Boczek, Michael W. Ware, Mary McKay, Jill M. Hoelle, Mary Schoen and Eric N. Villegas (2015) Determining Pathogen and Indicator Levels in Class B Municipal Organic Residuals Used for Land Application // Journal of Environmental Quality $2015 \quad 44: \quad 1$ : $265-274$ doi:10.2134/jeq2014.04.0142

104. DeLaune P. B. and P. A. Moore (2014) Factors Affecting Arsenic and Copper Runoff from Fields Fertilized with Poultry Litter // Journal of
Environmental Quality 2014 43: 4: 1417-1423 doi:10.2134/jeq2013.12.0495

105. Richard H. Grant and Matthew T. Boehm (2015) Manure Ammonia and Hydrogen Sulfide Emissions from a Western Dairy Storage Basin // Journal of Environmental Quality $2015 \quad 44: \quad 1$ : $127-136$ doi:10.2134/jeq2014.05.0196

106. Sazykina M.A., Sazykin I.S., Kostina N.V., Khmelevtsova L.E., Trubnik R.G., Sazykina M.I. (2014) Issledovanie ekotoksikologicheskikh parametrov stochnykh vod g. Rostova-na-donu i g. Myunkhena // Voda: khimiya i ekologiya. 2014. № 1 (66). pp. 3-10.

107. Helena Andersson, Lars Bergström, Barbro Ulén, Faruk Djodjic and Holger Kirchmann (2015) The Role of Subsoil as a Source or Sink for Phosphorus Leaching // Journal of Environmental Quality. Received: Apr 24, 2014. Published: January 16, 2015. Vol. 44 No. 2. pp 535-544. doi:10.2134/jeq2014.04.0186

108. Probirskiy MD, Pankova GA, Lominoga OA (2015) Opyt khimicheskogo udaleniya fosfornykh soedineniy iz stochnykh vod na kanalizatsionnykh ochistnykh sooruzheniyakh GUP «Vodokanal Sankt-Peterburga» // Vodoochistka. Vodopodgotovka. Vodosnabzhenie. 2015. № 1 (85). pp. 62-67.

109. Mitloehner F (2014) Agriculture infrastructure and farming practices: Responses to climate change and population growth // 248th ACS National Meeting \& Exposition. 13TH IUPAC International Congress of Pesticide Chemistry. Crop, Environment, and Public Health Protection. Technologies for a Changing World. Co-sponsored by IUPAC and ACS-AGRO. August 10-14, 2014. San Francisco, California, USA. Abstracts. AGRO 143. pp. 78

110. Kolychev AN (2013) O vykhode na lidiruyushchuyu pozitsiyu regional'noy sistemy obrashcheniya s otkhodami posredstvom razvitiya resursosberezheniya // XIV mezhdunarodnaya nauchno-prakticheskaya konferentsiya «Retsikling otkhodov». 4-7 dekabrya 2013 goda. Sankt-Peterburg. Rossiya.

111. Lentz RD, Ippolito JA (2014) Biochar and Manure Affect Calcareous Soil and Corn Silage Nutrient Concentrations and Uptake // Journal of Environmental Quality 2014 43: 2: 775-775 doi:10.2134/jeq2011.0126er

112. Ushakova NA (2014) Perspektivy promyshlennogo razvedeniya nasekomykh na tverdykh organicheskikh otkhodakh, polucheniya kormovogo belkovogo produkta i biologicheski aktivnykh veshchestv // Mezhdunarodnaya nauchno-prakticheskaya konferentsiya «Biotekhnologiya i kachestvo zhizni» 18-20 marta 2014 g. Moskovskiy 


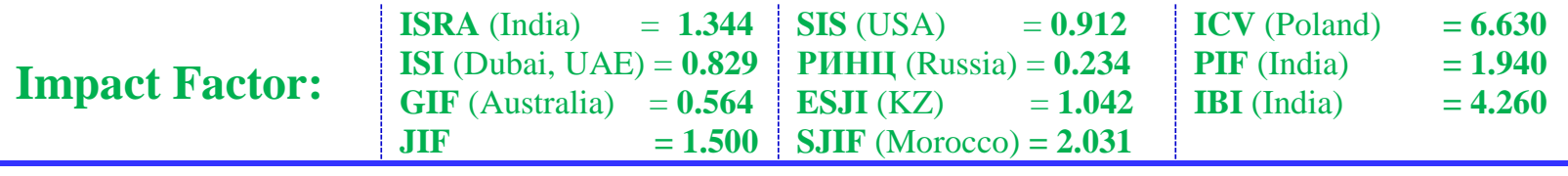

mezhdunarodnyy kongress «Biotekhnologiya: sostoyanie i perspektivy razvitiya». Moskva. 2014. pp. 414. Available: www.mosbiotechworld.ru (Accessed: 10.04.2016).

113. (2016) STEINERT Elektromagnetbau $\mathrm{GmbH}$ Available:

http://www.steinertglobal.com/grp/de/ (Accessed: 10.04.2016).

114. (2016) TOMRA Available: https://www.tomra.com/en/solutions-andproducts/sorting-solutions/recycling (Accessed: 10.04.2016).

115. Akanova NI (2013) Fosfogips neytralizovannyy - perspektivnoe agrokhimicheskoe sredstvo intensifikatsii zemledeliya (po materialam seminarov OAO «MKhK» EvroKhim) // Plodorodie. 2013. №1. C. 2-7. Available: http://plodorodie-j.ru/journal/2013-2/nomer11/n60.html (Accessed: 10.04.2016).

116. (2016)

Available:

https://en.wikipedia.org/wiki/Phosphogypsum (Accessed: 10.04.2016).

117. (2016) Piritnyy ogarok. Bol'shaya Entsiklopediya Nefti Gaza Available: http://www.ngpedia.ru/id205561p2.html

(Accessed: 10.04.2016).

118. Skuratov NS (2001) Agromeliorativnye priemy sokhraneniya i vosstanovleniya plodorodiya oroshaemykh chernozemov: dissertatsiya ... doktora sel'skokhozyaystvennykh nauk : 06.01.02. Novocherkassk, 2001. 376 p. 71 02$6 / 70-9$

Available:

http://www.dissercat.com/content/agromeliorati vnye-priemy-sokhraneniya-i-vosstanovleniyaplodorodiya-oroshaemykh-chernozemov (Accessed: 10.04.2016).

119. Kalinichenko VP (2010) Patent na izobretenie RU № 2387115 C2. Ustroystvo dlya vneseniya veshchestva pri rotatsionnom vnutripochvennom rykhlenii. Zaregistrirovano v Gosudarstvennom reestre izobreteniy Rossiyskoy Federatsii 27 aprelya 2010 g. Patentoobladatel' IPPYuR. Zayavka № $2008124500 / 12(029710)$ ot 16.06.2008. Opublikovana 27.04.2010. Byul. № 12. 6 p.: 2 il.

120. Gromyko EV, Mishchenko NA, Chernenko VV, Endovitskiy AP, Il'in VB, Bakoev SY, Kalinichenko VP, Statsko EV, Serenko VV, Zinchenko AV (2012) Teoreticheskie osnovy upravleniya veshchestvennym sostavom dispersnoy sistemy vnutrennikh sloev pochvy // Nauchnyy zhurnal Rossiyskogo NII problem melioratsii. 2012. №1. pp. 101-119. Available: http://www.rosniipm-

$\underline{\text { sm.ru/dl_files/udb_files/udb13-rec91-field6.pdf }}$ (Accessed: 10.04.2016).
121. Koval'skiy VV (1974) Geokhimicheskaya ekologiya. Moscow: Nauka, 1974. 299 p.

122. Endovitskiy AP, Kalinichenko VP, Ivanenko AA, Mishchenko NA (2011) Vliyanie melioratsii fosfogipsom na sostoyanie svintsa $\mathrm{i}$ kadmiya v chernozemakh // Agrokhimiya. 2011. № 10. pp. 58-69.

123. Endovitskiy AP, Kalinichenko VP, Minkina TM (2014) Sostoyanie svintsa i kadmiya V chernozeme posle vneseniya fosfogipsa // Pochvovedenie. 2014. № 3. pp. 340-350. DOI: 10.7868/S0032180X14030058

124. Endovitskii AP, Kalinichenko VP, Minkina TM, Mandzhieva SS, Sushkova SN (2014) Lead Status in Chernozem of the Krasnodar Krai After the Application of Phosphogypsum // Middle-East Journal of Scientific Research 22
(7): 954-959.
DOI:

10.5829/idosi.mejsr.2014.22.07.21980, 2014.

125. Osborne LR, Baker LL, Strawn DG (2014) Lead immobilization and phosphorus availability in phosphate-amended, minecontaminated soils // Journal of Environmental Quality. 2015. Jan; 44(1):183-90. doi: 10.2134/jeq2014.07.0323.

126. Torbert H. Allen and Dexter B. Watts (2014) Impact of Flue Gas Desulfurization Gypsum Application on Water Quality in a Coastal Plain Soil // Journal of Environmental Quality 2014 43: 1: 273-280 doi:10.2134/jeq2012.0422

127. Kalinichenko VP, Kodzoev MM, Tochiev AM, Mamilov BB, Bazgiev MA (2012) Soil ecosystem management in birdlime utilization // European researcher = Evropeyskiy issledovatel'. 2012. T. 25. № 7. pp. 1042-1049.

128. Awad YM, Blagodatskaya E, Kuzyakov Y, Ok YS (2012) Effects of polyacrylamide, biopolymer, and biochar on decomposition of soil organic matter and plant residues as determined by $14 \mathrm{C}$ and enzyme activities // European Journal of Soil Biology. 2012. T. 48. pp. 1-10. DOI: 10.1016/j.ejsobi.2011.09.005

129. Okolelova AA, Zheltobryukhov VF, Kalinkina ED (2013) Valovye i podvizhnye formy tyazhelykh metallov $\mathrm{v}$ pochvakh Volgograda. Ekologiya urbanizirovannykh territoriy. 2013. №4. $\quad$ pp. 45-48. Available:. http://www.volgau.com/Portals/0/static/izvestiy a_auk/izvestiya_2014_36_4.pdf (Accessed: 10.04.2016).

130. Okolelova Alla A, Tatyana G. Voskoboynikova, Ruslan O. Manov (2015) Improving the Properties of Light-brown Soil Using Hydrogel // Biogeosystem Technique. 2015. Vol.(3). Is. 1. pp. 82-88. DOI: 10.13187/bgt.2015.3.82

131. Petrenko DV, Belyuchenko IS (2012) Vliyanie otkhodov Belorechenskogo khimzavoda na soderzhanie $\quad \mathrm{Sr} \quad \mathrm{v}$ okruzhayushchikh 
landshaftakh // Ekologicheskiy vestnik Severnogo Kavkaza. 2012. T. 8. № 1. pp. 4-79.

132. Potatueva YA, Sidorenkova NK, Prishchep EG (2002) Agroekologicheskoe znachenie primesey tyazhelykh metallov i toksichnykh elementov v udobreniyakh // Agrokhimiya. 2002. № 1. pp. 85-95.

133. Mindubaev AZ, Voloshina AD, Kulik NV, Minzanova ST, Mironova LG, Yakhvarov DG, Alimova FK, Akhossiyenagbe SK, Bolormaa C (2013) Vozmozhnost' anaerobnoy biodegradatsii belogo fosfora // Ekologicheskiy Vestnik Severnogo Kavkaza. 2013. T. 9. № 2. pp. 4-15.

134. Favas Paulo, Joao Pratas, Maria H Gomes, V. Cala (2011) Selective Chemical Extraction of Heavy Metals in Tailings and Soils Contaminated by Mining Activity: Environmental Implication // Journal of Geochemical Exploration. 2011. №12. 111(3):160-171.

DOI: 10.1016/j.gexplo.2011.04.009

135. (2015) Commission Regulation (EU) $2015 / 1005$ of 25 June 2015 amending Regulation (EC) No 1881/2006 as regards maximum levels of lead in certain foodstuffs (Text with EEA relevance) // Official Journal of the European Union L $161 / 9$ 26.6.2015. Available:

http://www.iss.it/binary/lcdr2/cont/CR_2015_1 005.pdf (Accessed: 10.04.2016).

136. Anisimov Vjacheslav S., Lidia N. Anisimova, Ljudmila M. Frigidova, Dmitry V. Dikarev, Ruslan A. Frigidov, Ilja V. Kochetkov, Nanalia I. Sanzharova (2015) Evaluation of Migration Ability of $\mathrm{Zn}$ in the Soil-Plant System // Biogeosystem Technique. 2015. Vol.(4). Is. 2. pp. 153-163. DOI: $10.13187 /$ bgt.2015.4.153

137. Sokolov MS, Glinushkin AP, Toropova EY (2015) Sredoobrazuyushchie funktsii zdorovoy pochvy - fitosanitarnye i sotsial'nye aspekty // Agrokhimiya. 2015. № 8. pp. 81-94.

138. Minkina TM, Mandzhieva SS, Fedorov YA, Sushkova SN, Burachevskaya MV, Nevidomskaya DG, Antonenko EM, Kalinichenko VP, Endovitskiy AP, Il'in VB, Chernenko VV, Bakoev SY (2014) Patent RU №2521362 C2. Sposob otsenki stepeni degradatsii tekhnolandshafta pri khimicheskom zagryaznenii. MPK C01B (2006.01), E02B13/00, G01N33/24 . Zaregistrirovano v Gosudarstvennom reestre izobreteniy Rossiyskoy Federatsii 30 aprelya 2014 g. Zayavka №2012101597/20(002163) ot 17.01.12. Opublikovano 27.06.2014. Byul. №18. $7 \mathrm{p}$.

139. Kalinichenko VP, Il'in VB, Endovitskiy AP, Chernenko VV (2013) Patent na izobretenie RU №2476055 S2. Sposob sinteza veshchestva vnutri tonkodispersnoy sistemy. MPK K1. A01C 23/00 (2006.01). Zayavka № $2011100187 / 21(000278)$ ot 11.01 .2011$. Zaregistrirovano v Gosudarstvennom reestre izobreteniy Rossiyskoy Federatsii 27 fevralya 2013 g. Opublikovano 27.02.2013. Byul. №6. 7 p.: 2 il.

140. (2007) Veterinarno-sanitarnye pravila sbora, utilizatsii i unichtozheniya biologicheskikh otkhodov (utv. Glavnym gosudarstvennym veterinarnym inspektorom Rossiyskoy Federatsii 4 dekabrya 1995 g. N 13-7-2/469). S izmeneniyami i dopolneniyami ot 16 avgusta 2007. Available: http://base.garant.ru/2107950/ (Accessed: 10.04.2016).

141. Kalinichenko VP, Startsev VF (2015) Patent RU 2552076 C1. Sposob utilizatsii boenskikh otkhodov. MPK B09C 1/00 (2006.01) B09B 3/00 (2006.01) C09F 1/00 (2006.01) C08L 89/04 (2006/01). Zayavka № 2013154612/17(085276) ot 9.12.2013. 2406015. Zaregistrirovano v Gosudarstvennom reestre izobreteniy Rossiyskoy Federatsii 28 aprelya 2015 g. Opublikovano 10.06.2015. Byul №16. 9. p.: 1 il.

142. Ma L., C. Guo, X. Lü, S. Yuan, and R. Wang (2015) Soil moisture and land use are major determinants of soil microbial community composition and biomass at a regional scale in northeastern China // Biogeosciences 2015. №12. $\mathrm{pp}$ 2585-2596. www.biogeosciences.net/12/2585/2015/ doi:10.5194/bg-12-2585-2015

143. Minaudo C, Meybeck M, Moatar F, Gassama N, Curie F (2015) Eutrophication mitigation in rivers: 30 years of trends in spatial and seasonal patterns of biogeochemistry of the Loire River (1980-2012) // Biogeosciences. 2015. No12. pp 2549-2563.

www.biogeosciences.net/12/2549/2015/ doi:10.5194/bg-12-2549-2015

144. Kostychev PA (1937) Pochvy chernozemnoy oblasti Rossii, ikh proiskhozhdenie, sostav i svoystva / 1886. Pod red., s vvod. st. i primech. A.N. Sokolovskogo. M.; L.: OGIZ Sel'khozgiz, 1937. 239 p.

145. Vinogradskiy SN (1952) Mikrobiologiya pochv: Problemy i metody. M.,L.: Izd-vo AN SSSR, 1952. 793 p.

146. Blagodatskaya E, Kuzyakov Y, Blagodatsky S, Anderson TH (2014) Microbial Growth and Carbon Use Efficiency in the Rhizosphere and Root-free soil // PLoS ONE. 2014. T. 9. № 4. p. e93282. DOI: 10.1371/journal.pone.0093282

147. Cheshko Valentin T, Lida V. Ivanitskaya, Yulia V. Kosova (2014) Configuration of Stable Evolutionary Strategy of Homo Sapiens and Evolutionary Risks of Technological Civilization (the Conceptual Model Essay) // 
Biogeosystem Technique. 2014. Vol.(1). № 1. pp. 58-68. DOI: 10.13187/bgt.2014.1.58

148. Kolesnikov SI, Yaroslavtsev MV, Spivakova NA, Kazeev KS (2013) Sravnitel'naya Otsenka Ustoychivosti Biologicheskikh Svoystv Chernozemov Yuga Rossii K Zagryazneniyu CR, CU, NI, PB v model'nom eksperimente // Pochvovedenie. 2013. № 2. pp. 195.

149. Kolesnikov SI, Rotina EN, Kazeev KS (2013) Technology of evaluation methods of soil remediation effectiveness according to biological indicators // Middle East Journal of Scientific Research. 2013. T. 17. № 7. pp. 914918.

150. Lyashenko GM, Kalinichenko VP (2012) Technogenic pollution of soils by lead in catena of highway in the Priazovsky zone of the Rostov region // Scientific Journal of Russian Reserch Institute of Problems of Melioration, № 2(06), 2012. pp. 60-74. Available: http://www.rosniipmsm.ru/dl_files/udb_files/udb13-rec106field6.pdf (Accessed: 10.04.2016).

151. Xiong Tiantian, Thibault Leveque, Muhammad Shahid, Yann Foucault, Stéphane Mombo and Camille Dumat (2014) Lead and Cadmium Phytoavailability and Human Bioaccessibility for Vegetables Exposed to Soil or Atmospheric Pollution by Process Ultrafine Particles // Journal of Environmental Quality. 2014 43: 5: 1593-1600 doi:10.2134/jeq2013.11.0469

152. (2016) EUGRIS. Available: http://www.eugris.info/displayresource.aspx?r= 6993 (Accessed: 10.04.2016).

153. (2016) SanPiN 2.1.4.1074-01 Available: http://ross-water.com/files/sanpin/file2.pdf?1242648352 (Accessed: 10.04.2016).

154. (2016) Predel'no dopustimye kontsentratsii (PDK) khimicheskikh veshchestv $\mathrm{v}$ vode vodnykh ob"ektov khozyaystvenno-pit'evogo i kul'turno-bytovogo vodopol'zovaniya. Gigienicheskie normativy GN 2.1.5.1315-03

155. (2016) Orientirovochno-dopustimye kontsentratsii(ODK) khimicheskikh veshchestv $\mathrm{v}$ pochve. Gigienicheskie normativy. GN 2.1.7.2042-06.

156. (2016) US Environment Protection Agency. Risk-Based Screening Table - Generic Tables. Available: $\quad$ http://www2.epa.gov/risk/riskbased-screening-table-generic-tables (Accessed: 10.04.2016).

157. (2016) Land contamination: soil guideline values (SGVs) Available: https://www.gov.uk/government/publications/la nd-contamination-soil-guideline-values-sgvs (Accessed: 10.04.2016).

158. (2001) Soil Liquid Phase Composition. Editors: V.V. Snakin, A.A. Prisyazhnaya, E. KovácsLáng Elsevier Science B.V. 2001. Available:
https://books.google.ru/books?id=4qNfLt73bIg C\&pg=PA232\&lpg=PA232\&dq $=$ mpc $+c d+i n+s$ oil\&source $=$ bl\&ots $=$ iMBvJCnzz\&sig $=$ sejTK2 Gi_YULHlbxtyNx4e21rxg\&hl=ru\&sa=X\&ved= 0CEMQ6AEwBWoVChMI9prb55DlxwIVSJEs Ch2pYQzE\#v=onepage \&q $=$ mpc\%20cd\%20in $\% 20$ soil\&f=false (Accessed: 10.04.2016).

159. (2000) Cadmium in fertilisers. Risks from cadmium accumulation in agricultural soils due to the use of fertilisers containing cadmium Model estimations October 2000. Available: http://ec.europa.eu/enterprise/sectors/chemicals/ files/reports/denmark_en.pdf (Accessed: 10.04.2016).

160. Il'in VB (2012) Tyazhelye metally i nemetally v sisteme pochva-rastenie / Otv. red. A. I. Syso. Novosibirsk: Nauka, 2012. 220 s. ISBN: 978-57692-1229-1 BBK: P032.34,07 P127.252,07

161. Batukaev AA, Zarmaev AA, Kalinichenko VP, Chulkov VV, Mamilov BB, Chernenko VV, Lokhmanova OI (2012) Patent na izobretenie RU №2498550 S2. Sposob sozdaniya mnogoletnikh nasazhdeniy. MPK A01B 79/02. Zayavka № 2012102879(004261) ot 27.01.2012. Zaregistrirovano v Gosudarstvennom reestre izobreteniy Rossiyskoy Federatsii 20 noyabrya 2013 g. Opublikovano 20.11.2013. Byul. №32. 4 p.: il.

162. Batukaev Abdul-Malik A., Anatoly $P$. Endovitsky, Andrey G. Andreev, Valery P. Kalinichenko, Tatiana M. Minkina, Zaurbek S. Dikaev, Saglara S. Mandzhieva, and Svetlana N. Sushkova (2016) Ion association in water solution of soil and vadose zone of chestnut saline solonetz as a driver of terrestrial carbon sink // Solid Earth, 7, Issue, 2, 415-423, doi:10.5194/se-7-415-2016

163. (2016) Atmospheric Methane: Sources, Sinks, and Role in Global Change / Edited: M.A.K. Khalil. NATO ASI Serries. Series I. Environmental global change. V. 13. DOI 10.1007/978-3-642-84605-2

164. Lea Steinle, Christina Bethke, Johanna Schweers, Hermann Bange, Annette Kock, Moritz F. Lehmann, Tina Treude, and Helge Niemann (2014) Aerobic methane oxidation in a coastal environment with seasonal hypoxia a time series study // Geophysical Research Abstracts. EGU General Assembly 2014.DOI Vol. 16, EGU2014-6636-3.

165. Galanin AV (2012) Litobiosfera Zemli. 2012. Available: http://ukhtoma.ru/litobiosphere.htm (Accessed: 10.04.2016).

166. Kiselev AA, Reshetnikov AI (2013) Metan v rossiyskoy Arktike: Rezul'taty nablyudeniy i raschetov // Problemy Arktiki i Antarktiki. 2013. № 2 (96). pp. 5-15.

167. Drewniak BA, U. Mishra, J. Song, J. Prell, and VR. Kotamarthi (2015) Modeling the impact of 


\begin{tabular}{|c|c|c|c|c|c|c|}
\hline Impact Factor: & $\begin{array}{l}\text { ISRA (India) } \\
\text { ISI (Dubai, UAF } \\
\text { GIF (Australia) } \\
\text { JIF }\end{array}$ & $\begin{array}{l}=1.344 \\
=0.829 \\
=0.564 \\
=1.500\end{array}$ & $\begin{array}{l}\text { SIS (USA) } \\
\text { PИНЦ (Russia } \\
\text { ESJI (KZ) } \\
\text { SJIF (Morocco }\end{array}$ & $\begin{array}{l}=\mathbf{0 . 9 1 2} \\
=\mathbf{0 . 2 3 4} \\
=\mathbf{1 . 0 4 2} \\
=\mathbf{2 . 0 3 1}\end{array}$ & $\begin{array}{l}\text { ICV (Poland) } \\
\text { PIF (India) } \\
\text { IBI (India) }\end{array}$ & $\begin{array}{l}=6.630 \\
=1.940 \\
=4.260\end{array}$ \\
\hline
\end{tabular}

agricultural land use and management on US carbon budgets // Biogeosciences. 2015. №12. pp 2119-2129.

Www.biogeosciences.net/12/2119/2015/ doi:10.5194/bg-12-2119-2015

168. Caldararu S, Purves DW, Palmer PI (2014) Phenology as a strategy for carbon optimality: a global model // Biogeosciences. 2014. Vol. 11, $\begin{array}{llll}\text { No } 3 . & \text { pp. 763-778 }\end{array}$ www.biogeosciences.net/11/763/2014/ doi:10.5194/bg-11-763-2014

169. Eric F. Wood (2014) The Challenges of Developing a Framework for Global Water Cycle Monitoring and Predicting. // Alfred Wegener Medal Lecture. EGU General Assembly. Vienna, 2014. Wednesday, 30, April 31.

170. Orlenok VV (2009) Rol' endogennogo faktora v izmenenii urovnya okeana za poslednie 140 let // Vestnik Rossiyskogo gosudarstvennogo universiteta im. I. Kanta. 2009. Vyp. 1. pp. 817.

171. Bondarenko AL (2014) Krupnomasshtabnaya dinamika i dolgoperiodnye volny Mirovogo okeana i atmosfery. M.: 2014. 206 p.

172. Borisenkov EP, Pichugin YA (2001) Vozmozhnye negativnye stsenarii dinamiki biosfery kak rezul'tat antropogennoy deyatel'nosti // Doklady akademii nauk. 2001. T. 378. №6. pp. 812-814.

173. Rhodes Rachael, Edward Brook, John Chiang, Thomas Blunier, Hai Cheng, R. Lawrence Edwards, Olivia Maselli, Joseph McConnell, Daniele Romanini, Jeffrey Severinghaus, Todd Sowers, and Christopher Stowasser (2014) Continuous methane record of abrupt climate change 10-68 ka: sighting Heinrich events in the ice core record // Geophysical Research Abstracts. EGU General Assembly. Vienna, 2014. DOI Vol. 16, EGU2014-7984

174. Blunier T, Bender ML, Barnett B, von Fischer JC (2012) Planetary fertility during the past 400 ka based on the triple isotope composition of $\mathrm{O} 2$ in trapped gases from the Vostok ice core // Climate of the Past. 2012. №8. pp. 1509-1526. doi:10.5194/cp-8-1509-2012

175. Erwan Monier, David Kicklighter, and Andrei Sokolov (2014) Future changes in terrestrial carbon fluxes over Northern Eurasia under uncertainty in 21st century climate change // Geophysical Research Abstracts. EGU General Assembly. Vienna, 2014. DOI: Vol. 16, EGU2014-9763

176. Ziska L (2014) Carbon dioxide, climate change, pest biology, and management: A new paradigm for the 21st century // 248th ACS National Meeting \& Exposition. 13TH IUPAC International Congress of Pesticide Chemistry. Crop, Environment, and Public Health Protection. Technologies for a Changing World. Co-sponsored by IUPAC and ACS-AGRO. August 10-14, 2014. San Francisco, California, USA. Abstracts. AGRO 143. pp. 78.

177. Lisetskii FN, Rodionova ME (2015) Transformation of Dry-Steppe Soils Under Long-Term Agrogenic Impacts in the Area of Ancient Olbia // Eurasian Soil Science. 2015. T. 48. № 4. pp. 347-358. DOI: 10.1134/S1064229315040055

178. Lisetskii FN, Pavlyuk YV, Kirilenko ZA, Pichura VI (2014) Basin organization of nature management for solving hydroecological problems // Russian Meteorology and Hydrology. 2014. Vol. 39. №. 8. pp. 550-557. DOI: $10.3103 / \mathrm{S} 106837391408007 \mathrm{X}$

179. Rashid Saeed, Muhammad Ishfaq, Urooj Ishfaque, Zeeshan Fareed, Bushra Zulfiqar, Farrukh Shahzad (2014) Effect of Greenhouse Gases on Agriculture Production in Pakistan // Biogeosystem Technique. 2014. Vol.(1). №1. pp. 85-88. DOI: $10.13187 /$ bgt.2014.1.85

180. Hewett Caspar, Jonathan Dick, Oksana Tarasova, Barbara Ferreira, Mark Wilkinson, and Paul Quinn (2014) Geoengineering the climate: the way forward? // Great Debates. GDB2. EGU General Assembly. Vienna, 2014. Thursday, 1, May.

181. (2016) Parnikovye gazy Available: https://ru.wikipedia.org/wiki/ (Accessed: 10.04.2016).

182. Moskalenko Aleksandr P., Stanislav A. Moskalenko (2015) System Technologic Complexes as Organizational and Economic Basis of Resource-saving and Energy Efficiency // Biogeosystem Technique. 2015. Vol.(3). Is. $1 . \quad$ pp. 64-81. DOI: 10.13187/bgt.2015.3.64

183. Semenov AM, Sokolov MS (2016) Kontseptsiya zdorov'ya pochvy: fundamental'no-prikladnye aspekty obosnovaniya kriteriev otsenki // Agrokhimiya. 2016. № 1. pp. 3-16.

184. (2016) Available: https://en.wikipedia.org/wiki/Noosphere (Accessed: 10.04.2016).

185. (2016) Available: https://en.wikipedia.org/wiki/Gaia hypothesis (Accessed: 10.04.2016). 